\title{
1 Marco teórico y estado de la cuestión
}

El marco teórico de esta investigación gira alrededor de tres aspectos fundamentales. En primer lugar, definiremos las distintas categorías o clases de palabras en las que se integran las unidades analizadas: adjetivos y adverbios, así como, desde una perspectiva pragmática o discursiva, marcadores, operadores o conectores. A continuación, expondremos el estado de la cuestión, esto es, las investigaciones publicadas sobre precisamente, justo, etc. Por último, contrastaremos los diversos modelos teóricos (gramaticalización, pragmaticalización, subjetivización o cooptation) que describen los macrocambios; es decir, los cambios que engloban varios niveles lingüísticos -en este caso, principalmente semántica y sintaxis-.

\subsection{Terminología básica y clasificación}

\subsubsection{Adjetivos y adverbios}

Un término que abarca tanto a los adjetivos como a los adverbios es el de modificadores: «Modification is a linguistic function that refers to a semantic change operated on a primary unit, e.g. a word or a sentence» (Valera/Hummel 2017, 1). Es decir, la característica común de adjetivos y adverbios es que proyectan su contenido semántico sobre el segmento oracional al que modifican. Ya Carbonero Cano $(1978,175)$ opina que los adverbios son signos de carácter principalmente modificador, dado su vínculo con el adjetivo. Esta propiedad funcional también se expresa en el término atributo, propuesto por Hummel $(2000,478$; 2012) como hipónimo de las denominaciones tradicionales de las clases de palabras adjetivo y adverbio: ambos atribuyen sus rasgos semánticos conceptuales a otra unidad lingüística. La atribución es, pues, la función sintáctica de los adjetivos y adverbios (Hummel 2012; 2015, 226).

En cuanto a los adjetivos, en la bibliografía se ha constatado que adscriben propiedades a un sustantivo; son elementos caracterizadores (Demonte Barreto 1999, 133; Martínez 2009, 1227). En concreto, este es el caso de los adjetivos calificativos, que designan cualidades. Por el contrario, los adjetivos determinativos «introducen el grupo nominal y delimitan su denotación especificando a cuántas y cuáles de las entidades designadas por el nombre hace referencia el hablante» (NGLE 2009, §13.1d). Concretamente, se trata de demostrativos, posesivos, numerales, indefinidos y relativos (Alarcos Llorach 2005, 83). Tanto los 
adjetivos calificativos como los determinativos concuerdan en género y número con el sustantivo modificado.

Para los adjetivos, se distinguen dos posiciones sintácticas básicas: la atributiva y la predicativa. Los adjetivos predicativos funcionan como predicado de una oración copulativa. En cambio, los adjetivos atributivos se posicionan en el interior de un sintagma nominal, son atributos o modificadores nominales (Demonte Barreto 1999, 133-136; Pastor 2016, 369). ${ }^{1}$

Los adjetivos atributivos pueden posponerse o anteponerse al sustantivo al que modifican. En la bibliografía, se distinguen básicamente cuatro grupos en cuanto a las posibilidades posicionales (Almela Pérez 2000; Alarcos Llorach 2005, 84; Fuentes Rodríguez 2006):

a) adjetivos relacionales siempre pospuestos: español, geométrico, físico...

b) adjetivos determinativos siempre antepuestos: aquellos, mero, propio, presunto...

c) adjetivos calificativos que cambian de significado al cambiar la posición: pobre, grande, antiguo, viejo, cierto, alto...

d) adjetivos calificativos que pueden aparecer en ambas posiciones y mantienen su significado: difícil, pequeño, oscuro, verde, dulce, blanco, estúpido, maravilloso...

Nos centraremos en el cuarto grupo, ya que este es el caso de los adjetivos analizados en este trabajo. Cuando los adjetivos calificativos aparecen pospuestos, delimitan el conjunto de objetos a los que se refiere el nombre y restringen su extensión: en los coches rojos se excluyen todos aquellos que no tienen la propiedad de ser rojos. En cambio, en la anteposición, los adjetivos calificativos del cuarto grupo no conllevan delimitación referencial. Por ejemplo, en la fresca hierba no se limita la extensión del sustantivo hierba, sino que simplemente se destaca una propiedad inherente de este (Rodríguez Ramalle 2005, 167). En otras palabras, el adjetivo antepuesto «revela una intención explicativa, descriptiva, de la realidad sugerida por el sustantivo» (Alarcos Llorach 2005, 82). En este sentido, los adjetivos del cuarto grupo mantienen su significado base en ambas posiciones, pero la anteposición es una posición marcada que conlleva

1 Esa clasificación no es general: la NGLE (2009, §13.11, §37) llama atributos a los adjetivos que ocurren con un verbo copulativo y modificadores o adyacentes nominales a los adjetivos adnominales. Asimismo, Alarcos Llorach (2005, cap. 26) llama atributos a aquellos elementos que toman la posición de predicado nominal de un verbo copulativo, entre ellos, los adjetivos; en cambio, los adjetivos adnominales son llamados adyacentes. Hummel (2015, 226), a su vez, usa el término atributo en un sentido amplio, que abarca tanto la modificación directa de un núcleo sintagmático, como la modificación indirecta a través de una predicación. 
una serie de valores como, por ejemplo, énfasis: la oscura noche, la blanca nieve (Almela Pérez 2000, 298). Además, los adjetivos adnominales antepuestos aportan sistemáticamente subjetividad (Fuentes Rodríguez 2006; 2013a; Hummel 2013c, 65).

Al contrario de los adjetivos, que muestran siempre concordancia con el sustantivo al que modifican, se suele postular que una de las propiedades principales, canónicas y definitorios de los adverbios es su invariabilidad (Kovacci 1999, 707-708; Alarcos Llorach 2005, 128; NGLE 2009, 2285). Por lo demás, el grupo de los adverbios está formado por un inventario heterogéneo. Especificaremos a continuación la clasificación según su estructura morfológica (NLGE 2009, $\S 30.2 \mathrm{a}-\mathrm{c})$. En primer lugar, hay una serie de adverbios simples con forma propia, es decir, no derivados: allí, así, bien, mal, etc. (Kovacci 1999, 707; NGLE 2009, 2288); entre ellos, por ejemplo, los de tiempo hoy, ayer, nunca, siempre, etc., cuyo origen léxico remite al latín (Espinosa Elorza 2010, 102). En segundo lugar, existen dos procedimientos morfosintácticos para formar adverbios a partir de adjetivos, uno de derivación y otro de conversión:

a) El sufijo -mente se añade a gran parte de los adjetivos inmovilizados en su forma femenina singular: solamente, fácilmente, etc. (Kovacci 1999, 708-712; Alarcos Llorach 2005, 129), como es el caso de los adverbios justamente, precisamente y exactamente.

b) Los adverbios cortos son adverbios con forma adjetival, llamados también adverbios adjetivales o adjetivos adverbializados. ${ }^{2}$ Estos adverbios tienen la misma forma que los adjetivos correspondientes, pero carecen de flexión de género o número: correr rápido, volar bajo, respirar hondo, jugar limpio, etc. Se trata de un inventario reducido que generalmente cuenta con una contrapartida adverbial en -mente (Kovacci 1999, 712-715; Alarcos Llorach 2005, 128; NGLE 2009, §30.3). En este grupo se inserta, por ejemplo, justo como adverbio.

Por último, también pertenecen al inventario de los adverbios las locuciones adverbiales, compuestas por una preposición que se une a un sustantivo, adjetivo o adverbio: apenas, enfrente, a veces, a oscuras, en realidad, de repente, etc. (Kovacci 1999, 707; Alarcos Llorach 2005, 133).

2 En este trabajo, usaremos sistemáticamente la denominación adverbio corto, simplemente por razones estilísticas y de legibilidad: se diferencia mejor del término adjetivo que los términos adjetivo adverbializado o adverbio adjetival. 
Según Hummel (2014c; 2015, 227), dicha diversidad formal corresponde a cuatro tipos de realización morfosintáctica de la función atributiva:

a) el sistema monocategorial, que usa una sola categoría morfológica sin distinguir adverbio de adjetivo: la chica rápida, correr rápido.

b) el sistema bicategorial, que diferencia una marca morfológica para el adverbio: correr rápidamente.

c) adverbio léxico: bien, mal, despacio, etc.

d) paráfrasis: con rapidez.

Los adverbios en -mente pertenecen, pues, al segundo sistema, mientras que el uso adverbial de justo refleja un sistema monocategorial. El par justamente/justo se insiere en una serie bastante larga de «parejas» constituidas por un adverbio corto y un adverbio en -mente con la misma base léxica (Kaul de Marlangeon 2002, 76). En general, los adverbios en -mente y los correspondientes adverbios cortos se diferencian por el registro al que pertenecen preferentemente. La mayoría de los adverbios en -mente son cultismos que surgieron en la lengua escrita, sobre todo, literaria y solo llegaron parcialmente a la oralidad (Company Company 2014b, 530-532). En cambio, los adverbios cortos aparecen preferentemente en el registro informal y en la oralidad. La conversión de la forma masculina inmovilizada del adjetivo es un mecanismo productivo para la formación de adverbios heredado del latín. El español conservó este tipo de adverbios cortos desde el latín hablado hasta la actualidad por medio de la lengua oral (Bosque 1989, 131; Hummel 2014a, 625-628).

Aunque el adverbio en -mente y el adverbio corto con la misma base léxica son, en principio, conmutables en determinados contextos, también muestran diferencias en cuanto a su comportamiento sintáctico, semántico o pragmático. Así, por ejemplo, los adverbios en -mente muestran mayor flexibilidad sintáctica (Garcés Gómez 2002; Company Company 2017).

Desde el punto de vista sintáctico, la clase de los adverbios es altamente polifuncional, ya que estos pueden modificar a diversas partes de la oración, lo que complica su delimitación y clasificación funcional (Domínguez de RodríguezPasques 1968, 293; Carbonero Cano 1978; Kovacci 1999, §11.3; NGLE 2009, 2285). Como sugiere su denominación, los adverbios están destinados, en principio, a cumplir por sí solos el papel de adyacente circunstancial del verbo (Alarcos Llorach 2005, 128). En este caso, son «adverbios calificativos» (Carbonero Cano $1978,194)$ que caracterizan el verbo de igual manera que el adjetivo correspondiente califica a un sustantivo.

Además, los adverbios pueden aparecer como adyacentes de otras partes de la oración, tales como adjetivos u otro adverbio distinto (Carbonero Cano 1978; Alarcos Llorach 2005, 128). En síntesis, la función de los adverbios (en -mente) es la modificación «de la significación de una propiedad» (Kaul de Marlangeon 
2002, 150) y esta puede estar expresada por un sustantivo, un adjetivo, un participio, un verbo $\mathrm{u}$ otro adverbio.

Dependiendo, pues, de la unidad modificada, Kovacci $(1999,725)$ diferencia entre dos grupos de adverbios: los nucleares, que se relacionan con el predicado de la oración (modificadores del verbo o de sintagmas adjetivos y adverbiales) y los periféricos, que son externos al dictum porque modifican a las funciones nucleares en su conjunto.

Otra diferenciación habitual en esta misma línea es la de adverbios adjuntos, disjuntos y conjuntivos (Quirk et al. 1972, §5.44). Adjuntos son los que modifican un elemento concreto de la oración. En cambio, los disjuntos y conjuntivos aparecen como unidades independientes; los primeros indican la actitud del hablante ante el enunciado y los segundos conectan enunciados (Fuentes Rodríguez 1987, 60; Kaul de Marlangeon 2002, 50-52). Los adverbios disjuntos son los que generalmente se denominan «adverbios oracionales» (González Ruiz 2000, 291) y los adverbios conjuntivos son conectores que explicitan un nexo semántico entre constituyentes coordinados o subordinados (Kovacci 1999, 769). Espinosa Elorza (2010) asigna las siguientes subcategorías a los tres tipos principales:

a) adverbios adjuntos: de lugar, de tiempo, de aspecto, de modo, focalizadores, de afirmación, de negación, de duda, relativos e interrogativos.

b) adverbios disjuntos: de enunciación o acto verbal, de enunciado, temáticos o de tópico.

c) adverbios conjuntivos: aditivos, adversativos, consecutivos o conclusivos, explicativos, reformuladores, ejemplificadores, rectificadores, recapituladores, de ordenación, de apoyo argumentativo, de digresión.

A su vez, Kaul de Marlangeon (2002, cap. 3.4) establece tres funciones sintácticas principales de los adverbios: la función circunstancial (de tiempo, de modo, de lugar...), la función modificadora (por ejemplo, la focalización) y la función modalizadora o modificadora de modalidad (que indica la actitud del hablante ante lo enunciado o la enunciación).

\subsubsection{Marcadores discursivos, conectores y operadores pragmáticos}

Mientras que en el análisis puramente gramatical la unidad mayor es la oración, el análisis del discurso va más allá de la oración: trata de la unión de varias oraciones y de su jerarquía u organización. A su vez, el nivel superior al discurso es el texto (Garrido 2016, 7). La pragmática, por otra parte, analiza la lengua como instrumento de comunicación, teniendo en cuenta todos los aspectos que contribuyen a la interpretación del mensaje. Es decir, se ocupa de los aspectos 
relacionados con los interlocutores, la situación comunicativa y el contexto del enunciado (Escandell Vidal 2016, 257-260). A este respecto, preferimos desambiguar el término tan generalizado de contexto siguiendo la distinción entre discurso y pragmática. Por un lado, a nivel discursivo, entendemos como contexto puramente lingüístico el co-texto, es decir, el segmento lingüístico anterior y posterior a una unidad analizada. Por otro lado, el contexto pragmático alude a toda la situación extralingüística en la cual se emite un enunciado.

Así, Ghezzi $(2014,14)$ habla de tres planos pragmáticos y discursivos, o mejor dicho, un plano discursivo (la cohesión y coherencia textual) y dos planos pragmáticos: la dimensión social (la relación entre los interlocutores) y la expresión del punto de vista personal del hablante (hacia su discurso, el interlocutor o el contexto de la interacción).

Más detallada es la distinción de Fuentes Rodríguez (2017, 11), quien diferencia entre cuatro planos discursivo-pragmáticos básicos. Primero, el plano enunciativo involucra al hablante como constructor de la enunciación, su responsabilidad e implicación en su discurso. En segundo lugar, el plano modal es el que muestra la actitud subjetiva del hablante. En tercer lugar, el plano informativo tiene que ver con el estatus de la información comunicada (nueva o conocida) y la focalización de ciertas partes del enunciado como segmentos relevantes. Por último, en el plano argumentativo entran las estrategias que emplea el hablante para convencer al oyente de su tesis.

A su vez, Briz Gómez/Pons Bordería/Portolés Lázaro (2008) reconocen las siguientes cuatro funciones discursivas o pragmáticas: la conexión entre dos miembros discursivos, la modalización (intensificación o atenuación), la focalización y el control de contacto.

Las unidades léxicas que codifican instrucciones respecto al discurso o a las inferencias pragmáticas, es decir, que entran en los planos mencionados, suelen recibir diversas denominaciones y clasificaciones y forman un grupo altamente heterogéneo. Para los adverbios y adjetivos que nos ocupan, conviene definir los términos marcadores del discurso, partículas discursivas, operadores y conectores, así como adverbios de foco.

Portolés Lázaro (2016) usa el término partículas discursivas como el más general y abarcador, que incluye marcadores del discurso, conjunciones, interjecciones y adverbios de foco. Asimismo, Llopis Cardona (2014, 25-30) emplea partícula discursiva como hiperónimo. En cambio, Hummel (2012, 7-8) prefiere el término signo discursivo para dejar claro que se trata de signos lingüísticos con forma y contenido, y no de partículas sin significado conceptual.

De acuerdo con la diferenciación entre pragmática y discurso, Ghezzi (2014, 15) diferencia entre marcadores discursivos y marcadores pragmáticos. Los primeros refieren a la estructuración del discurso, señalan las relaciones 
intradiscursivas y especifican cómo el mensaje o su contenido se relaciona con el discurso siguiente o la situación extralingüística. Los segundos, los marcadores pragmáticos, son las unidades que tienen un significado subjetivo o intersubjetivo, esto es, que expresan la opinión subjetiva del hablante o indican la relación social entre los interlocutores.

No se trata de clases cerradas de signos que sean propia y exclusivamente discursivos o pragmáticos, sino que generalmente se aprovechan categorías gramaticales preexistentes para expresar nuevas funciones discursivas o pragmáticas: adjetivos (bueno), adverbios (bien), formas verbales (digamos), grupos preposicionales (o sea), sustantivos (hombre), etc. (Hummel 2012, 7; 2013c, 68). Esto explicaría, pues, la heterogeneidad formal de los signos discursivos o marcadores discursivos.

La distinción entre micro y macrosintaxis de Fuentes Rodríguez (2017, 13) llamado también micro y macroestructura (Fuentes Rodríguez 2013b) - alude a esa doble organización lingüística. En la microsintaxis, contamos con clases de palabras como adjetivo o adverbio, que se estudian tradicionalmente en la oración (Fuentes Rodríguez 2017, 7), mientras que en la macrosintaxis, estas tienen una función pragmática o discursiva. La creación de unidades lingüísticas que operan en la macrosintaxis (es decir, marcadores discursivos o conectores y operadores, en la terminología de la autora) se sirve de unidades de la microsintaxis. Pongamos como ejemplo Sinceramente, esperaba mejor nota. En la microsintaxis, sinceramente es un adverbio, pero en macrosintaxis actúa como una unidad específica del plano enunciativo que marca la implicación personal del enunciador (Fuentes Rodríguez 2017, 13).

En cuanto a la definición canónica de los marcadores discursivos, esta se sustenta en criterios morfosintácticos y en su papel discursivo-pragmático:

«Los marcadores del discurso son unidades lingüísticas invariables, que no ejercen una función sintáctica en el marco de la predicación oracional -son, pues, elementos marginales- y que poseen un cometido coincidente en el discurso: el de guiar, de acuerdo con sus distintas propiedades morfosintácticas, semánticas y pragmáticas, las inferencias que se realizan en la comunicación» (Martín Zorraquino/Portolés Lázaro 1999, 4057).

La función principal de los marcadores del discurso consiste en relacionar un enunciado con la situación discursiva y, en especial, con la interacción entre hablante y oyente, así como indicar actitudes del hablante $u$ organizar el texto (Heine 2013, 1211). Así pues, los marcadores del discurso incluyen estructuradores de la información (primero, por último...), conectores (además, por tanto...), reformuladores (o sea, es decir...), marcadores de control del contacto (¿no?) y, además - según algunos autores-, operadores discursivos (en realidad, desde luego...) (Portolés Lázaro 2016, 693-696). En cambio, Llopis Cardona (2014, 77-78) separa los operadores de los marcadores discursivos y, entre los marcadores 
discursivos, distingue entre conectores argumentativos, reformuladores y estructuradores de información (función metalingüística o metadiscursiva), así como marcadores de modalización (intensificación o atenuación) y marcadores de interacción.

Llopis Cardona $(2014,25-30)$ considera que los operadores forman una categoría propia dentro de las partículas discursivas y quedan fuera de la categoría de los marcadores del discurso, porque no son extraoracionales, sino que inciden sobre todo el enunciado o sobre alguno de sus componentes. Es decir, los operadores no salen de los límites de su propio enunciado. Mientras que los conectores ligan su enunciado con otro anterior (explícito o implícito), los operadores no exigen un segmento previo para ser entendidos; pueden aparecer integrados en la oración o entre pausas, pero su ámbito no excede los límites del enunciado (Fuentes Rodríguez 2003, 68; 2017, 15). Como alcance o ámbito se entiende el segmento afectado por el operador:

«Consideramos alcance (scope) el elemento al que afecta la función macro[e]structural de una unidad o construcción. No se trata de rección, sino del segmento al que se dirige su acción como modal, enunciativo, focalizador, etc.» (Fuentes Rodríguez 2017, 22).

El alcance pragmático de un operador puede recaer sobre todo el enunciado o solo en un segmento. Por ejemplo, en Desgraciadamente, tampoco esta semana me ha tocado la primitiva, el alcance del operador modal desgraciadamente atañe a todo el enunciado. En cambio, en Desgraciadamente para ti, tampoco esta semana me ha tocado la primitiva, solo un segmento parcial es afectado por el alcance del operador (Fuentes Rodríguez 2017, 22).

Los operadores se mueven en todos los planos discursivos: marcan la modalidad o la enunciación, u operan en la macroestructura informativa o argumentativa. Así, Fuentes Rodríguez (2003; 2009) distingue entre operadores modales (afortunadamente, en realidad), operadores enunciativos (en el fondo, sinceramente, en realidad, en definitiva), operadores atenuativos (de algún modo, en cierto modo), operadores argumentativos (incluso, solo, al menos, hasta, solamente) y de focalización informativa (precisamente, justamente, ¿no?, ¿verdad?, en realidad, en el fondo). Por consiguiente, la subclase de los operadores que nos atañe en este trabajo es la de los adverbios de focalización, integrada por adverbiales como solo, incluso, precisamente, justo, particularmente, etc. (NGLE 2009, 2991).

La concepción de operadores de Fuentes Rodríguez (2009; 2013a) excede a la clase tradicionalmente considerada como marcadores discursivos, ya que no solo permite incluir los adverbios, sino que también tiene en cuenta adjetivos. Asimismo, Hummel $(2012,9)$ propone el término de signos discusivos de base atributiva, que abarca tanto adverbios como adjetivos con función discursiva. Nos atenemos a esta concepción amplia, ya que comprobaremos que también 
los adjetivos base (justo, preciso, exacto y cabal) ocasionalmente adoptan valores discursivos y/o pragmáticos.

En cuanto a la semántica de los marcadores discursivos -y de los signos discursivos en general, incluyendo los operadores- se ha postulado que su significado suele ser más bien procedimental y no conceptual (Martín Zorraquino/ Portolés Lázaro 1999, §63.1.4; Murillo Ornat 2010; Heine 2013, 1209). Mientras que las palabras con significado conceptual aportan representaciones conceptuales, las palabras procedimentales codifican instrucciones de procesamiento, guían la interpretación del enunciado al imponer restricciones sobre las inferencias pragmáticas (Escandell Vidal/Leonetti 2004; Blakemore 2007; Escandell Vidal/Leonetti/Ahern 2011) y manipulan las representaciones conceptuales (Llopis Cardona 2016, 233).

La separación entre significado conceptual y procedimental no es nítida, ya que las palabras con significado procedimental pueden seguir manteniendo su significado conceptual subyacente, por lo que hay palabras que combinan ambos significados (Escandell Vidal/Leonetti/Ahern 2011, xxiv). En este sentido, los marcadores discursivos tienen fundamentalmente un significado procedural o de procesamiento, aunque pueden guardar huellas de las unidades conceptuales de las cuales se originaron. Dicho de otro modo: a los significados conceptuales retenidos se les impone otro procedimental (Portolés Lázaro 2016). Es más, el significado conceptual base muchas veces condiciona e influye en los valores procedimentales de los marcadores discursivos (Murillo Ornat 2010, 270).

Por último, los marcadores discursivos tienen un significado no restrictivo, es decir, no forman parte del significado proposicional de una oración (Heine 2013, 1210). De ahí su opcionalidad sintáctica y semántica: la omisión de un marcador no vuelve el discurso agramatical ni incomprensible, pero sí más difícil de procesar (Heine 2013, 1212). La eliminación de un marcador discursivo complica las inferencias pragmáticas, pero estas instrucciones, cuando no se codifican explícitamente, pueden deducirse también del contexto (Furkó 2014, 291).

\subsection{Estado de la cuestión: estudios sobre precisamente, justo, justamente, etc.}

Nuestro repaso de la bibliografía publicada sobre justo, preciso, exacto, cabal y sus correspondientes adverbios en -mente sigue dos vertientes principales: la investigación sincrónica que se centra en los usos pragmático-discursivos de los adverbios de exactitud en el español actual y la investigación sobre la diacronía de estos lexemas. A pesar de que la lengua investigada es el español, nos parece útil tener en cuenta también estudios de los correlatos en francés e inglés. Según 
De Cesare (2015), en su artículo Defining Focusing Modifiers in a cross-linguistic perspective, no solo hay correspondencias y solapamientos entre el inventario de los focalizadores de varios idiomas genéticamente relacionados, sino que estos también comparten características semánticas y sintácticas. Para mostrarlo, De Cesare (2015), recopila un inventario de modificadores focales en inglés, francés, italiano y alemán. Entre ellos, se encuentran los siguientes correlatos a los adverbios exactamente, precisamente, justamente y justo (De Cesare 2015, 56):

Inglés: exactly, just, precisely

Francés: exactement, justement, précisément

Italiano: esattamente, precisamente

Este inventario podría completarse, además, por otras lenguas romances: en portugués, existen justo, preciso y exa(c)to, con los correspondientes adverbios en -mente (Machado 1967, s.v. justo, preciso, exato); en catalán just/justament, exacte/exactament, precís/precisament (Grup Enciclopèdia Catalana); y en rumano se usan como adjetivos y adverbios just, exact y precis (Ciorănescu 2007; Vinereanu 2009). ${ }^{3}$

Como señala Hummel (2013b), el hecho de que una amplia serie de adverbios con función discursiva aparece de manera paralela no solo en las lenguas romances, sino que también cuenta con correlatos en inglés (absolutamente/absolutely, realmente/really, exactamente/exactly...) se debe a una tradición cultural compartida. Estos adverbios no necesariamente remontan a una tradición oral común del latín vulgar, sino que - al tratarse de formaciones adverbiales cultas- lo más probable es que el uso de ciertos adverbios discursivos se deba a la imitación de un modelo cultural, sobre todo, del francés.

Consiguientemente, dado que algunos usos discursivos, por ejemplo, del inglés just o del francés justement coinciden a grandes rasgos con sus correlatos españoles, los estudios diacrónicos sobre estas voces pueden indicarnos también posibles vías de desarrollo en español, sobre todo, porque los usos pragmáticos del español precisamente, justo, etc., han sido escasamente estudiados desde una perspectiva histórica. Solamente existen análisis históricos para justo y justamente, que, además, derivan de estudios sobre la diacronía de sus correlatos en

3 En el caso del alemán, los focalizadores que desempeñan funciones similares, ausgerechnet, genau o gerade, no están emparentados etimológicamente con justo, exactamente, precisamente, etc., de origen latino, aunque podríamos añadir el cultismo alemán just, que no consta en el inventario de De Cesare (2015). Aparte, los préstamos präzise y exakt se usan en alemán como adjetivos de exactitud con significado conceptual. 
inglés y francés. En lo que respecta a preciso/precisamente y exacto/exactamente, nos basamos en entradas lexicográficas y en un breve apartado de Espinosa Elorza (2014, §9.4.2.5) sobre la diacronía de los adverbios de exactitud. Por último, la diacronía de cabal y cabalmente no está suficientemente documentada en los diccionarios consultados y queda todavía por descubrir.

\subsubsection{Estudios diacrónicos}

Consultamos varios diccionarios históricos, como el Dictionnaire historique de la langue française (= DHLF 2000), el diccionario histórico con enfoque panrománico de Meyer-Lübke (1935) y el diccionario etimológico del francés de von Wartburg et al. (= FEW 1922-2002). Para el español, los datos ofrecidos por Alonso (1958), Corominas/Pascual (1997) y Covarrubias Orozco ([1611] 1995) son menos detallados y, en ocasiones, contradictorios e incompletos. Además, consultamos los diccionarios antiguos recogidos en el Nuevo tesoro lexicográfico de la lengua española (= NTLLE 2001) y los diccionarios de referencia del latín como el Thesaurus Linguae latinae (= TLL 2009), el Oxford Latin dictionary de Glare (2012) o los diccionarios latín-español como los de Blánquez (2012), Segura Munguía (2013) y de Miguel ([1867] 2000).

Tanto los diccionarios históricos consultados como el breve repaso a los adverbios de exactitud de Espinosa Elorza $(2014,1047)$ concuerdan en el origen latino de tres lexemas de nuestro grupo: justo y justamente derivan del adjetivo IŪSTUS 'justo, correcto, legal, legítimo, que observa el derecho, según la justicia', mientras que EXĀCTUS es el participio de EXIGERE 'exigir, expulsar, pesar', con lo cual significaba 'pesado con exactitud'. Por último, PRAECĪSUs 'cortado, abrupto, abreviado, conciso' es el participio de PRAECIDERE 'cortar bruscamente, cortar por delante'.

Según Alonso (1958, s.v. justo), el adjetivo español justo 'según la justicia, derecho’ se documenta desde el siglo XII y el adverbio justo 'exacto’ es más tardío: aparece en el siglo XVIII. Espinosa Elorza (2014, 1047) ofrece las siguientes fechas para la aparición de los adverbios de exactitud en español: el cambio de justamente 'con justicia' > 'exactamente' se produce entre los siglos XV y XVI y el adverbio corto justo 'exactamente' se usa desde el XVII. Sin embargo, nuestro análisis de justamente y justo (Gerhalter 2016) basado en corpus históricos muestra una aparición más temprana: tanto justo (adjetivo y adverbio) como justamente se documentan con el valor de exactitud desde el siglo XV y se consolidan en el XVI.

En cuanto al cambio semántico de ‘según la justicia, derecho' > 'exacto', que se observa tanto en el inglés just, en el francés juste y en el español justo, este ha sido analizado por varios autores. Especialmente el inglés just ha despertado el interés, ya que se trata de una palabra especialmente polisémica y polifuncio- 
nal en inglés. Son numerosos los estudios a lo largo de varias décadas. Cohen (1969) fue de los primeros en plantear la pregunta: How did the English word 'just' acquire its different meanings? A su vez, Traugott (1988) reconstruye el desarrollo semántico y pragmático de just desde su significado original 'correcto, legal' a los nuevos significados como 'exacto'. Una escala de valores, en la que lo deseable es el punto medio equilibrado, es la que interviene en este cambio semántico: la interpretación de algo justo y correcto, que está hecho de acuerdo a las normas sociales, infiere que está hecho con el debido balance y con exactitud (Traugott 1988, 136).

En esta misma línea, Santos Domínguez (1998) reflexiona sobre aspectos semánticos en su breve contribución Pragmática y cambio semántico: los adjetivos 'justo', 'puro' y 'mero'. Según él, determinadas inferencias pragmáticas explican la evolución semántica de estos tres adjetivos. Para el adjetivo justo, se basa esencialmente en las observaciones de Traugott (1988) sobre el inglés just: la evolución del significado de justo 'exacto' a partir del significado originario 'legal, correcto’ se explica por una escala de normas sociales donde los extremos no son tolerados. Lo aceptable y deseable se encuentra en un punto medio. Por tanto, lo justo conlleva la inferencia de que se hace con el adecuado equilibrio y balance. Tras consolidarse el nuevo significado 'preciso, exacto', se extiende a nuevos contextos de medidas, lugares o momentos (Santos Domínguez 1998, 359-361).

Los adjetivos preciso y exacto aparecen en los siglos XVI y XVII, respectivamente (Alonso 1958, s.v. preciso, exacto). Asimismo, Espinosa Elorza $(2014,1047)$ constata el uso de exactamente y precisamente desde el siglo XVI. Como subraya Espinosa Elorza $(2014,1047)$, la cronología del grupo de los adverbios focalizadores de exactitud «resulta sorprendente». Esta observación parece referirse al hecho de que son fechas de aparición bastante tardías: ninguno de los cuatro adverbios de exactitud (justamente, justo, precisamente, exactamente) - ni los correspondientes adjetivos de exactitud- parecen haberse usado con anterioridad al siglo XV.

En latín, los adverbios de exactitud eran otros: COMMODUM o DEMUM (Espinosa Elorza 2014, 1047). El adjetivo commodus significa 'acomodado', 'proporcionado', 'apropiado', 'ajustado', 'conveniente', como en el ejemplo commodius TEMPUS ANNI 'el momento más oportuno del año’. De este adjetivo derivan los adverbios соммодuм 'oportunamente', 'al tiempo', 'al punto', 'precisamente', 'convenientemente' у соммоDĒ 'justa, precisa, perfectamente’ (Segura Munguía 2013, s.v. Commodus). Por otro lado, el adverbio DËMUM significa tanto 'justamente', 'exactamente', 'precisamente' como ‘sola y únicamente' y 'por fin, finalmente, al cabo': ANNO DEMUM QUINTO ‘al cabo de los cinco años’ (Segura Munguía 2013, s.v. DEMUM).

El hecho de que ninguno de los adverbios de exactitud del latín, соммоDUM, COMMODĒ y DĒMUM, se mantuvo en español (o en el caso de cómodo, no 
con este significado) abre un interrogante desde la perspectiva onomasiológica: al parecer, el español anterior al siglo XV carece de adverbios y adjetivos de exactitud o, en todo caso, no hay documentación escrita de tales lexemas. Por consiguiente, planteamos la pregunta de investigación de si fue cabal/cabalmente el lexema que «llenaba» el vacío onomasiológico en los adjetivos y adverbios de la lengua medieval.

En cuanto a la diacronía de cabal, las indicaciones son contradictorias: según Alonso (1958, s.v. cabal), data del siglo XV, mientras que Corominas/Pascual (1997, s.v. cabo) datan la aparición de cabal ya en el siglo XII. Es el único lexema del grupo que no se remonta hasta el latín, sino que es una formación iberorromance sobre la base sustantiva cabo 'extremo, final'. No cuenta con correlatos ingleses o franceses, pero sí portugueses (Machado 1967, s.v. cabal).

Los diccionarios consultados no ofrecen suficientes datos sobre cabal/ cabalmente, por lo cual es necesario un estudio empírico basado en un corpus para comprobar nuestra hipótesis según la cual estos serían el primer adjetivo y adverbio de exactitud en español. Llama la atención que Espinosa Elorza $(2014,1047)$ no tiene en cuenta el lexema cabal/cabalmente para el grupo de los adverbios de exactitud, pero sí menciona el uso de cabal 'perfectamente, justamente' como adverbio de afirmación de uso muy marginal en el español mexicano del siglo XVIII (Espinosa Elorza 2014, 1056-1057). No lo relaciona, pues, con los adjetivos y adverbios de exactitud. En todo caso, las citas decimonónicas de cabalmente en el Diccionario histórico de la lengua española ${ }^{4}$ (= DHLE) (19331936, s.v. cabalmente) indican que se usaba como equivalente a precisamente y justamente en el siglo XIX.

Curiosamente, los adverbios de foco de aproximación -que expresan lo opuesto a los adverbios de exactitud-cuentan con una documentación ininterrumpida desde el latín: ya en el siglo XIII se documenta casi, que procede de latín QUASI. Del mismo siglo datan el hoy anticuado hascas o fascas, el adverbio fusionado y gramaticalizado apenas, así como la locución poco más o menos. Además, se integran en el paradigma de los adverbios de aproximación elementos como

4 Del Diccionario histórico de la lengua española, redactado entre 1933 y 1936, solamente se llegaron a publicar dos tomos: el de la letra $A$ (1933) y el de B-Ce (1936). Por eso, hay entradas de cabal y cabalmente, pero no de los demás lexemas que nos interesan. A base de este diccionario se redactó un primer tomo del Diccionario histórico de la lengua española (1960-1996), que abarca las entradas correspondientes a A-APASANCA/B-BAJOCA (por lo cual, no comprende ningún lexema de los que nos interesan). Ambos diccionarios, incompletos, son los precursores del Nuevo diccionario histórico del español (NDHE), que está siendo elaborado actualmente y del que se han publicado algunas entradas en línea. A fecha de la redacción de este trabajo, todavía no se ha publicado ninguna entrada para los adjetivos o adverbios en cuestión. El corpus base de este nuevo diccionario histórico es el que usamos en el presente estudio (el CDH). 
cerca, alrededor $\mathrm{y}$, finalmente, también adverbios en -mente: aproximadamente (desde el siglo XVIII) y prácticamente (siglo XX para el uso de focalizador de exclusión) (García Pérez 2013a, 360-386). Es un grupo bastante amplio, heterogéneo y diversificado en cuanto a la procedencia y constitución morfológica de las voces: además de los mencionados (casi, apenas, poco más o menos, hascas/fascas, cerca, alrededor, aproximadamente), también se integran en este grupo bien, sobre, por poco (Espinosa Elorza 2010, 143) y escasamente (Kaul de Marlangeon 2002, 119).

En este sentido, frente al paradigma heterogéneo de los adverbios de aproximación, que se documentan desde los primeros textos castellanos, el paradigma de los adverbios de exactitud es más reducido, homogéneo y tardío. Llama la atención la aparente falta de adverbios de foco de exactitud en los textos medievales y cabe preguntarse si la aproximación es más frecuente y de cierta manera más necesaria para la comunicación que la focalización de exactitud. Los marcadores de aproximación una especie de, como, tipo, etc., han sido investigados, por ejemplo, por Mihatsch (2010) y como estrategia discursiva de hedging en el marco teórico de la atenuación (Kaltenböck/Mihatsch/Schneider 2010). En cambio, el procedimiento opuesto - la focalización de exactitud- no ha despertado el mismo interés en los estudios pragmáticos.

Ese tipo de asimetrías entre funciones opuestas se da también en otros dominios. Por ejemplo, Hummel $(2012,169)$ observa que el paradigma de los marcadores de negación es muy reducido en comparación con el paradigma especialmente productivo y abierto de los marcadores de afirmación. El autor opina que la naturaleza predominantemente cooperativa de la comunicación da pie a un mayor uso de signos afirmativos. Asimismo, Caffi (2007, 39-40) observa la tendencia universal a que, en todas las lenguas investigadas, las estrategias de atenuación (mitigation) ocurran con más frecuencia que las estrategias de intensificación.

Por lo tanto, nos parece probable que la atenuación mediante expresiones de aproximación (esto es, el hedging) sea una necesidad comunicativa más urgente que la focalización de exactitud, que sería un procedimiento de intensificación. Por lo general, las expresiones lingüísticas no son del todo exactas (lo que se denomina fuzziness) y no se suelen corresponder perfectamente con la realidad o las intenciones del hablante. En este sentido, lo normal es que la expresión lingüística sea aproximativa y no exacta. Esto da pie a la mayor necesidad de indicar, mediante aproximadores, lo fuzzy de la expresión lingüística.

Por ejemplo, aproximadamente tres metros indica que la realidad discrepa del número indicado. En cambio, adjetivos como exacto - aplicados a un nombre de medida, por ejemplo, tres metros exactos - no aportan información nueva, sino que son redundantes al indicar simplemente que la cantidad real es la expresada (Kovacci 1999, 719). Es decir, también en exactamente tres metros el número real es el expresado $(3,00)$ y la cantidad denotada sigue siendo la misma. En cambio, 
en aproximadamente tres metros sí que cambia la denotación y la extensión referencial del número tres (por ejemplo, 2,95 o 3,02).

\subsubsection{Estudios de pragmática sincrónica}

Entre el grupo delimitado de adverbios estudiados en el artículo El adverbio de exactitud y aproximación (García-Page 1995), se encuentran también justamente, exactamente y precisamente. Estos adverbios funcionan como acotadores semánticos respecto de las palabras a las que modifican, ya que pretenden fijar con rigor matemático la precisión de una medida: exactamente un kilómetro. El autor centra su estudio en aspectos sintácticos como la movilidad de estos adverbios dentro de la estructura oracional y su cohesión con el sintagma modificado. Además, menciona la estrecha relación que mantienen algunos de los adverbios en -mente con el correspondiente adjetivo: exactamente un kilómetro, un kilómetro exacto.

El Diccionario de partículas (Santos Río 2003) dedica entradas a los adverbios exactamente, justamente y precisamente. Describe sus diversos usos pragmáticos como adverbios de exactitud que focalizan un sintagma, adverbios que implican casualidad, adverbios de réplica afirmativa y de cohesión temática. Además, aparecen entradas de justo y exacto, por ejemplo, como «palabras reactivas de asentimiento».

El Diccionario de conectores y operadores del español (Fuentes Rodríguez 2009) ofrece una breve descripción de los usos pragmáticos de los operadores en cuestión. En concreto, aparecen clasificados como operadores informativos (exactamente, justamente, justo, precisamente, preciso) y operadores modales de acuerdo (exactamente, exacto, justamente). ${ }^{5}$ Los operadores informativos resaltan la información proporcionada por el segmento focalizado y la señalan como relevante:

Este registro coloquial es precisamente el que plantea mayores dificultades. (Fuentes Rodríguez 2009, s.v. precisamente)

En este preciso momento. (Fuentes Rodríguez 2009, s.v. preciso)

No creo oportuno que justamente el día 14 cambien [...]. (Fuentes Rodríguez 2009, s.v. justamente)

Fue en ese justo momento que él me vio [...]. (Fuentes Rodríguez 2009, s.v. justo)

También indican que la información proporcionada es exacta: un decreto que se había hecho exactamente hace un año (Fuentes Rodríguez 2009, s.v. exactamente).

5 Justo no consta como operador modal de acuerdo en este diccionario (Fuentes Rodríguez 2009, s.v. justo). Sin embargo, como el uso afirmativo de justo está documentado en nuestro corpus, lo añadiremos a los operadores modales de acuerdo. 
Asimismo, Fuentes Rodríguez (1995-1996) analiza el uso discursivo de precisamente como focalizador de exactitud y adecuación y como respuesta afirmativa. Este adverbio se emplea especialmente para subrayar contradicciones o inconveniencias. Las encuestas en el habla urbana de Sevilla muestran que precisamente predomina en el nivel culto y que su frecuencia va bajando según se va descendiendo en el nivel social (Fuentes Rodríguez 1995-1996, 783). Creemos que esto se correlaciona con el estatus generalmente culto de los adverbios en -mente.

La misma autora analiza el comportamiento de determinados adverbios - entre ellos justamente, precisamente y exactamente - en el «entorno pregunta-respuesta» (Fuentes Rodríguez 1994). En los diálogos, estos adverbios responden a una pregunta total. Justamente y exactamente expresan acuerdo y confirman algo ya presupuesto por el interlocutor, mientras que precisamente resalta una afirmación poco esperada o muy oportuna (Fuentes Rodríguez 1994, 151).

El estudio más extenso de los valores pragmáticos de precisamente y justamente es el artículo 'Precisamente estaba pensando en ti'... 'Precisamente'y 'justamente' como partículas focalizadoras de coincidencia de López Samaniego (2007). El valor discursivo más frecuente de justamente y, sobre todo, de precisamente es el de focalizar coincidencias, especialmente, en el espacio o tiempo. De este valor básico derivan los distintos efectos pragmáticos: sorpresa, casualidades inoportunas... Ambos adverbios llaman la atención sobre la aparición de un elemento concreto entre todos los elementos posibles, que coincide con otro que ha aparecido anteriormente (López Samaniego 2007, 53):

¡Hombre! Precisamente estaba pensando en ti. (López Samaniego 2007, 57)

[...] su asombrosa modernidad, esa que lo convierte en clásico justamente porque siempre parece nuestro estricto contemporáneo. (López Samaniego 2007, 72)

Además, justamente es focalizador de exactitud (López Samaniego 2007, 48-50) y (más) precisamente reformulador de concreción (López Samaniego 2007, 50-53).

En el Diccionario de partículas discursivas del español (Briz Gómez/Pons Bordería/Portolés Lázaro 2008) solo constan justamente y precisamente. Ambos adverbios tienen dos entradas que corresponden a dos funciones discursivas: la focalización de coincidencias significativas y la focalización de exactitud en informaciones, sobre todo, temporales o locales. Estas entradas, elaboradas por López Samaniego, se basan en el artículo de la misma autora sobre justamente y precisamente (López Samaniego 2007) que acabamos de mencionar.

Los únicos autores que mencionan el adverbio cabalmente como «adverbio de coincidencia», con el significado 'a propósito', y como adverbio de «respuesta afirmativa» son Egea $(1979,221)$ y Santos Río (2003, s.v. cabalmente). Por 
lo tanto, queda por analizar en qué medida cabal y cabalmente presentan - en la actualidad o históricamente- usos pragmáticos relacionados con precisamente, justamente y exactamente.

Mientras que la mayoría de los estudios se centran en los adverbios en -mente o, de manera más marginal, en los usos adjetivales, los adverbios cortos han sido menos estudiados. Hummel (2012, 147, 157s.) analiza el perfil semántico, sintáctico y pragmático de justo, destacando su uso como «focalizador enfático de la referencia», que insiste en la relevancia comunicativa de algo. Justo indica una valoración subjetiva de lo focalizado e implica coincidencia. Asimismo, el autor analiza exacto como signo de afirmación (Hummel 2012, 161-163).

\subsubsection{Estudios de pragmática diacrónica}

La diacronía de los usos pragmáticos de justo, precisamente, exactamente, etc., como adverbios de foco, marcadores de afirmación o reformuladores ha sido escasamente estudiada para el español. Entre los estudios en otros idiomas, de nuevo destacan los análisis de pragmática diacrónica sobre el francés justement y el inglés just.

En cuanto al inglés just, las publicaciones son numerosas: Lee (1987; 1991) dedica dos artículos a los diversos usos del inglés just, con valores como ‘solo'6 que van más allá del español justo. Kishner/Gibbs (1996) analizan cómo los oyentes infieren el significado intencionado de just dependiendo del contexto lingüístico. El capítulo The interpersonal particle 'just' (Aijmer 2002, 4) analiza los distintos significados semánticos y los usos pragmáticos, resultados de la gramaticalización de just. Por último, Molina/Romano (2012) ofrecen un análisis semasiológico y onomasiológico del marcador inglés just y de su gramaticalización, pragmaticalización e (inter)subjetivización. Las autoras dan especial importancia al contexto en el que se pueden producir cambios y reinterpretaciones, y observan que la polisemización y gramaticalización de just parece haber llegado más lejos en inglés que en otros idiomas.

Asimismo, el francés juste presenta más usos pragmáticos que el español justo, como recoge el artículo L'emploi de 'juste' comme adverbe d'énonciation de Leeman (2004): usos como je ferme juste les fenêtres et j'arrive (Leeman 2004, 17) tienen su correlato en el inglés just 'solo', pero no se documentan en español.

6 El significado ‘solo’ no existe en el español justo. Sin embargo, Santos Río (2003) anota que ha encontrado usos de justo como adverbio de cuantificación ('sólo') en traducciones, pero considera que este uso todavía no está del todo acreditado. 
En cuanto al adverbio en -mente, mencionamos un breve artículo de Serça (1996), en el que analiza los distintos usos de justement como adverbio de coincidencia, de argumentación a favor y de argumentación inversa. Este último uso consiste en que justement invierte automáticamente la argumentación y equivale, por lo tanto, a un no. Asimismo, Bruxelles et al. (1982) y Anscombre/ Ducrot (1994, 228) mencionan el funcionamiento de justement como inversor argumentativo.

Este uso parece no existir en español, ya que justamente se usa como simple marcador de afirmación. En efecto, Gómez-Jordana (2010a; 2012) compara español justamente con el francés justement y observa que el adverbio francés ha evolucionado más rápido y antes, por lo que su valor pragmático como inversor de la argumentación ya se ha consolidado en francés, mientras que en español apenas ha cuajado y se documenta muy poco. Gómez-Jordana (2012) muestra que el adverbio francés está más avanzado en su desarrollo pragmático, por lo que cuenta con más usos y significados que su correlato español. En este sentido, el caso de justement y justamente encaja en la tendencia observada por Hummel (2013b): el francés es la lengua que sirve de modelo y cuyos usos discursivos se imitan en otras lenguas europeas.

Para el español justamente, Gómez-Jordana (2012) establece la siguiente diacronía: en el siglo XVIII aparece de vez en cuando un uso de coincidencia que se establece y expande en el siglo XIX. Según Gómez-Jordana (2012), el uso de justamente como respuesta afirmativa no es habitual en español (al contrario del francés justement), ya que esta función la desempeña precisamente. Asimismo, nuestra investigación sobre justamente y justo (Gerhalter 2016) muestra que, desde la segunda mitad del siglo XVIII, aparecen esporádicamente los usos pragmáticos de justamente como focalizador de coincidencia y como adverbio de afirmación. Ambos usos arraigan en el siglo XIX y se documentan algo más tardía y más escasamente en el adverbio corto justo.

A modo de resumen, las referencias citadas nos sirven de punto de partida para descubrir el desarrollo diacrónico de las diversas funciones discursivas en nuestro corpus, ya que - como ha mostrado este repaso bibliográfico- la diacronía general de justo, precisamente, exactamente, etc., en español ha sido poco estudiada, y aún menos, la diacronía de sus funciones discursivo-pragmáticas. Especialmente el caso de cabal/cabalmente queda por analizar. Los estudios citados nos dan valiosas pistas a seguir y nos plantean, por ejemplo, la necesidad de profundizar en la interrelación entre sintaxis, semántica y pragmática. Además, queda por analizar el paradigma en su conjunto, esto es, el desarrollo paralelo entre cada uno de los adjetivos, su correspondiente adverbio en -mente y, posiblemente, el adverbio corto y/o locución adverbial. 


\subsection{Esquematización de los adjetivos y adverbios seleccionados}

Para este estudio se han seleccionado adjetivos y adverbios con una misma base léxica. Consideramos familia léxica todos aquellos lexemas que remiten a la misma etimología, es decir, a la misma raíz léxica y, consecuentemente, derivan del mismo concepto semántico. En este sentido, aparte de adjetivos y adverbios, las respectivas familias léxicas, esquematizadas en la Tabla 1, también incluyen sustantivos, verbos y locuciones adverbiales:

Tabla 1: Familias léxicas.

\begin{tabular}{llll}
\hline adjetivo & adverbio & sustantivo & verbo \\
\hline preciso & precisamente & precisión & precisar \\
exacto & exactamente & exactitud & - \\
justo & justamente, al justo, justo & justicia, justeza & justificar (ajustar) \\
cabal & cabalmente, al cabal, al cabo de & cabo & acabar \\
\hline
\end{tabular}

La selección se basa principalmente en un criterio onomasiológico: los adjetivos y adverbios comparten un significado común, el de exactitud, por lo que son intercambiables en varios contextos. En este sentido, además de la perspectiva semasiológica, que necesariamente adopta cualquier estudio de lexemas polisémicos (por ejemplo, la polisemia de justo o preciso), analizaremos desde un punto de vista onomasiológico la diacronía del grupo o paradigma. Tal y como advierte Hummel $(2012,187)$, los análisis onomasiológicos que se centran, por ejemplo, en el inventario de signos que aparecen en un uso discursivo concreto suelen pasar por alto las redes polifuncionales de cada signo y, por consiguiente, las motivaciones semánticas y funcionales subyacentes a cada signo discursivo particular. En el caso de los adjetivos y adverbios seleccionados, su simetría semántica, funcional y pragmática nos permite combinar ambas vertientes: la polifuncionalidad de cada lexema y las relaciones paradigmáticas entre ellos. A continuación, definiremos estos dos conceptos centrales.

7 El verbo ajustar, igual que la acepción de justo 'apretado', en realidad viene de un cruce con otro lexema latino, la preposición IUXTA 'cerca' (véase apartado 3.1.6). Es un caso de colisión homonímica que, por lo tanto, fusiona dos famílias léxicas distintas. 


\subsubsection{Onomasiología y paradigmas}

Los elementos de un paradigma son equivalentes funcionalmente y comparten una característica lingüística común, ya sea de índole semántica, morfológica, pragmática o fonológica. Esa concepción del «eje paradigmático», que se opone al «eje sintagmático», remite a la lingüística estructuralista de Saussure (Bosque 2007, 189; Estellés Arguedas 2009, 183-184).

Las denominaciones más corrientes para un grupo de lexemas con significados equivalentes son campo léxico, campo semántico o campo onomasiológico (Martínez 2003; Hummel 2012, 187). Según Coseriu (1998, 459) se trata de relaciones paradigmáticas entre palabras: «[e]l campo es el paradigma básico del léxico: es la estructura constituida por unidades léxicas (〈lexemas`) que se reparten entre sí una zona de significación común hallándose en oposición inmediata las unas con las otras». Así pues, un campo léxico es el conjunto de lexemas sinónimos que se relacionan por un contenido común y se oponen por rasgos distintivos mínimos o semas (Miguel 2016, 175). Generalmente, el concepto de campo se aplica a sustantivos concretos cuyos semas son fácilmente descriptibles. Por ejemplo, el campo léxico «de manual» es el de los asientos: silla, sillón, taburete, puf y sofá (Miguel 2016, 175).

La presente investigación gira alrededor de adjetivos y adverbios con un significado abstracto que difícilmente se puede describir en términos de semas, por lo cual basaremos el análisis semántico en los diversos contextos de uso, esto es, en las variantes contextuales que adopta el concepto de exactitud: por ejemplo, en lo referente al tiempo (véase apartado 4.2.2.1) o en lo referente a la expresión lingüística (véase apartado 4.2.1). En un mismo contexto (por ejemplo: adjetivos que caracterizan el mismo sustantivo o adverbios de modo que caracterizan el mismo verbo) es probable que los lexemas del grupo aporten matices semánticos distintos.

Más que campo semántico, usaremos principalmente el término paradigma para aquellos adjetivos y adverbios que pueden ocupar un mismo hueco funcional y que son, por lo tanto, intercambiables. Según Bosque (2007, 189), el paradigma consiste en aquella serie de elementos léxicos «entre los que se opta en cada contexto particular en función de las diferencias que los oponen». Mientras que los paradigmas «gramaticales» son esencialmente cerrados, es decir, cuentan con un inventario fijo, los paradigmas de elementos «léxicos» suelen ser abiertos.

Por ejemplo, los adverbios propiamente «léxicos» con la terminación en -mente forman un paradigma abierto (NGLE 2009, 2290). En cambio, los adverbios focales, entre los cuales se incluyen exactamente, justo, solo, incluso, etc., forman un paradigma adverbial «gramatical» y con ello un inventario cerrado (NGLE 2009, 2290-2291). Aun así, como destaca Bosque (2007, 190), incluso 
paradigmas cerrados, como ciertos paradigmas adverbiales, pasan a ser abiertos si se incluyen locuciones adverbiales. En efecto, vamos a tener en consideración también locuciones como al justo, al cabal o al cabo de.

La diversidad funcional de los adverbios ha llevado a muchos autores a agruparlos en paradigmas. Por ejemplo, el paradigma de los adverbios y locuciones adverbiales de la modalidad epistémica está formado por la serie quizá, tal vez, a lo mejor, acaso, igual, posiblemente, probablemente, seguramente y con seguridad (Suárez Hernández 2018). En este caso, son adverbios de procedencia morfológica distinta: adverbios con forma propia, adverbios adjetivales, adverbios en -mente y locuciones adverbiales. Coinciden en su significado base, la expresión de la certeza, aunque hay una diferenciación semántica interna según el menor o mayor grado de certeza (Suárez Hernández 2018, 242).

Para una clasificación más estructurada, hablamos de macroparadigmas que se subdividen en subparadigmas o microparadigmas. ${ }^{8}$ Por ejemplo, Kaul de Marlangeon (2002, véase el anexo) divide los adverbios de cuantificación (en -mente) en dieciocho grupos. Cada paradigma desempeña una función concreta, es decir, un tipo de cuantificación. La autora opina que, en lugar de clasificar los adverbios según el contenido semántico de su base lexemática (es decir, el adjetivo base), es preferible agruparlos en paradigmas sintácticos. Como paradigma sintáctico entiende la relación entre el adverbio modificador y la propiedad modificada (Kaul de Marlangeon 2002, 57). Emplea, por lo tanto, un criterio sintáctico: el paradigma está constituido por aquellos adverbios que aparecen en un mismo hueco funcional y modifican un mismo elemento oracional. El microparadigma que nos atañe en este trabajo, exactamente, justamente, precisamente, también engloba - para la función cuantificadora- estrictamente (Kaul de Marlangeon 2002, véase el anexo).

En relación a los cuantificadores, Bosque $(2007,191)$ habla de un paradigma cerrado de cuantificadores nominales que se asemejan a expresiones adverbiales y adjetivales: mucho, poco, bastante, demasiado, tanto, cuanto, más y menos. En este mismo dominio, Hummel (2013d, 251-252) agrupa demasiado, bastante, medio, poco, etc., bajo el paradigma de los «atributos cuantificadores».

También hay onomasiología en el nivel de los signos propiamente discursivos, es decir, en la constitución o formación de marcadores discursivos. De acuerdo con Fuentes Rodríguez $(2017,11)$, la lengua dispone de elementos específicos para cada plano discursivo (enunciativo, modal, informativo y argumentativo), es decir, hay paradigmas completos que van ampliándose según las

8 Agradezco a Stefan Schneider la sugerencia de introducir los conceptos de macro y microparadigma. 
necesidades del hablante y, al mismo tiempo, perdiendo elementos en desuso. En este sentido, Fuentes Rodríguez $(2017,11)$ habla de una cierta dinámica creativa.

Adoptamos el término paradigma pragmático de Estellés Arguedas (2009; 2011), quien lo describe como grupo de marcadores discursivos semánticamente equivalentes y que comparten un significado procedimental. Las unidades de un paradigma se distinguen entre sí por diferencias en su capacidad distribucional al seleccionar contextos distintos. También difieren en su frecuencia o en su grado de polifuncionalidad. Cada paradigma suele contar con un elemento central: el elemento no marcado, más prototípico y frecuente, y que menos restricciones de contexto muestra (Estellés Arguedas 2011, 155-157).

Asimismo, Hummel $(2012,187)$ usa el término de paradigma funcional para agrupar, desde una perspectiva onomasiológica, todos aquellos signos discursivos que se usan para una misma función discursiva (por ejemplo, la afirmación). Advierte que no suelen ser perfectamente conmutables - especialmente a raíz de diferencias conceptuales en los lexemas base- y que hay que analizar la diferenciación interna de los paradigmas y las frecuencias de uso.

A modo de ejemplo, enumeramos algunos paradigmas pragmáticos que recientemente han sido estudiados en su conjunto desde un punto de vista histórico:

a) Los marcadores de reconsideración: en definitiva, al fin y al cabo, al fin y a la postre, a/en fin de cuentas, después de todo (Garcés Gómez 2009).

b) Los marcadores de reformulación y corrección: digo, mejor dicho, quiero decir, qué digo, es decir, más bien, más aún, vamos, bueno, o sea (Garcés Gómez 2010).

c) Los marcadores de digresión: por cierto, a propósito, a todo esto/a todas estas, dicho sea de paso (Estellés Arguedas 2009; 2011); presentan intersecciones con el paradigma de los adverbios de modalidad epistémica: por cierto, ciertamente, verdaderamente, seguramente, realmente, en realidad (Villar Díaz 2013).

d) Los marcadores de separación: en todas maneras, de todas maneras, de todas suertes, de todos modos, de todas formas, en cualquier caso, en todo caso (Garcés Gómez 2011).

e) Los adverbios evidenciales que refuerzan la aserción: evidentemente, incuestionablemente, indudablemente, naturalmente, obviamente (Sánchez Jiménez 2013).

f) Los operadores discursivos matizadores de la veracidad y del enunciado: aparentemente, en apariencia, al parecer, a lo que parece, por lo que parece, dizque, por lo visto, supuestamente, pretendidamente, presuntamente, presumiblemente (Garcés Gómez 2013a).

g) Los marcadores argumentativos escalares: hasta, incluso, encima, para colmo, como si fuera poco, para más inri (Fuentes Rodríguez 2013c). 
En los paradigmas mencionados, no todos los elementos expresan la instrucción discursiva o pragmática en la misma medida o con la misma fuerza; es decir, aportan matices distintos y tienen distintas distribuciones de uso. Además, los elementos tienen orígenes formales diversos (adverbios, locuciones adverbiales que integran adjetivos, sustantivos o verbos) y provienen de conceptos semánticos distintos ('certeza', 'verdad', 'propósito', 'parecer', 'decir', etc.).

En cambio, en nuestro caso, todas las unidades son adjetivos y adverbios y cada par proviene de la misma base léxica. Además, todos ellos comparten un campo semántico común, el de la exactitud. Al contrario de los paradigmas enumerados arriba, el paradigma que va a ser objeto de estudio es homogéneo y cuenta con una notable cohesión semántica, funcional y formal. La asimetría más destacable es el uso de justo como adverbio corto:

adjetivo: en el momento justo/preciso/exacto/cabal

adverbio corto: justo/ ${ }^{\star}$ preciso $/{ }^{\star}$ exacto/ ${ }^{\star}$ cabal en este momento

adverbio en -mente: justamente/precisamente/exactamente/cabalmente en este momento

Además, quedan por integrar las locuciones adverbiales al justo y al cabal.

\subsubsection{Polifuncionalidad}

El término polifuncionalidad o multifuncionalidad suele referirse al hecho de que los marcadores discursivos generalmente desempeñan varias funciones en el discurso: un mismo marcador aparece con distintas funciones en distintas ocurrencias, y también es posible que realice varias funciones simultáneamente (Llopis Cardona 2014, 78).

Según Ghezzi (2014, 12-13), los marcadores pragmáticos y discursivos son multifuncionales en dos sentidos. Por un lado, dependiendo de su posición, entonación o contexto, un mismo marcador puede desempeñar diversas funciones, a veces incluso opuestas. Por otro lado, un mismo marcador en una determinada posición y en un determinado contexto indica diversos planos pragmático-discursivos a la vez e instruye simultáneamente diversos procedimientos (Ghezzi 2014, 13). Respecto a esa multifuncionalidad, Fuentes Rodríguez $(2017,11)$ observa que los cuatro planos discursivos (enunciativo, modal, informativo y argumentativo) funcionan de manera modular, ya que un mismo operador o conector puede desempeñar varias funciones macroestructurales - es decir, funciones en la macrosintaxis - a la vez.

La multifuncionalidad ya fue aludida por Schiffrin (1987) en su estudio fundamental sobre marcadores discursivos. Los marcadores analizados (oh, well, 
so, because, I mean, etc.) aparecen en más de una categoría; por lo tanto, tienen funciones primarias y secundarias: information state, participation framework, ideational structure, action structure, exchange structure (Schiffrin 1987, 315-317).

De acuerdo con Hummel (2012), extendemos el término polifuncionalidad a una concepción más abarcadora que incluye también las funciones sintácticas de las unidades base, esto es, las funciones adjetivales y adverbiales básicas. Como observa también Heine $(2013,1212)$, la multifuncionalidad no es una característica exclusiva de los marcadores discursivos, ya que también palabras léxicas o gramaticales son multifuncionales.

Basándonos en las clasificaciones de Espinosa Elorza (2010) y Kovacci (1999), precisamente, justamente, justo, exactamente y cabalmente aparecen en cuatro clases de adverbios: son adverbios adjuntos de modo, adverbios adjuntos focalizadores de particularización, adverbios adjuntos de afirmación y adverbios conjuntivos reformuladores. Asimismo, según la clasificación de Kaul de Marlangeon (2002, cap. 3.4), los adverbios en cuestión aparecen en las tres categorías: son adverbios circunstanciales (de modo), adverbios modalizadores de la enunciación (más precisamente [Kaul de Marlangeon 2002, 69]) y adverbios modificadores (de focalización).

De todo ello deducimos que los adjetivos y adverbios de exactitud entran en tres macroparadigmas pragmáticos: la focalización, la afirmación y la reformulación. Los adverbios en cuestión son polifuncionales porque no se limitan a una sola función (la de adverbios de modo), sino que se extienden a otras categorías. Dicho de otro modo: los adverbios de exactitud participan en varios paradigmas y cada cual corresponde a una función pragmático-discursiva y a un comportamiento sintáctico concretos. Además, los correspondientes adjetivos de exactitud también son polifuncionales, ya que aparecen -aunque de manera más marginal- como marcadores de afirmación, focalizadores y reformuladores.

Los tres macroparadigmas (focalización, afirmación y reformulación) contienen también otros signos. Es decir, los adjetivos y adverbios de exactitud no forman un macroparadigma pragmático exclusivo o propio, sino que comparten cada una de las tres funciones con otros signos, esto es, se solapan con otros microparadigmas distintos. Mientras que la mayoría de los estudios lexicográficos consultados tiene en cuenta la polifuncionalidad discursiva de los adjetivos y adverbios en cuestión (Santos Río 2003; López Samaniego 2007; Briz Gómez/Pons Bordería/Portolés Lázaro 2008; Fuentes Rodríguez 2009), la bibliografía centrada en los marcadores discursivos suele pasar por alto el uso de exactamente, justo, etc., como marcadores de afirmación y, aún más, de reformulación, ya que son miembros periféricos de ambos paradigmas. El macroparadigma de afirmación está constituido por miembros centrales como sí, ciertamente, por supuesto, 
desde luego, naturalmente, etc., (Espinosa Elorza 2010, 146) y el paradigma de reformulación-rectificación por unidades prototípicas como más bien o mejor dicho (Espinosa Elorza 2010, 168).

Nos atenemos a la definición de polifuncionalidad propuesta por Hummel (2012; 2013c), quien propone una definición paralela a la de polisemia: la polifuncionalidad hace referencia a las funciones verticalmente motivadas por la unidad lingüística base subyacente y/o motivadas horizontalmente entre funciones derivadas. Las funciones básicas subyacentes son categoriales, derivan de las propiedades de las clases de palabras (adjetivos, adverbios, etc.) y de sus funciones sintácticas (Hummel 2013c, 76). De manera paralela al núcleo semántico de un signo polisémico, la función categorial básica - por ejemplo, la atribución - forma el núcleo de un signo polifuncional. Así, la polifuncionalidad hace referencia a la motivación funcional que subyace a las funciones discursivas realizadas por un signo discursivo. Tanto los significados base como las funciones categoriales base son responsables de las diferencias entre diversos signos discursivos de un paradigma (Hummel 2012, 11-13). Como señala Hummel (2012, 7), los signos atributivos - adjetivos y adverbios- mantienen su función modificadora: atribuyen su significado conceptual a unidades mayores, tales como los enunciados o el discurso.

Además, polisemia y polifuncionalidad no solo se conciben como términos complementarios, sino que la relación entre ambas es motivada; cada significado corresponde típicamente a una función sintáctica específica. Consiguientemente, Hummel (2013c, 65) sostiene la hipótesis de que nuevos conceptos polisémicos tienden a aparecer en contextos sintácticos específicos.

En este sentido, analizaremos cómo las funciones sintácticas básicas de los adverbios de modo (modificadores de verbos) y de los adjetivos calificativos influyen o condicionan su uso como focalizadores y como marcadores de afirmación y reformulación.

En el plano pragmático-discursivo, no todas las unidades del grupo analizado son igual de polifuncionales. Por ejemplo, exacto como signo discursivo es monofuncional, ya que su única función discursiva parece ser la afirmación. En cambio, justo y justamente son polifuncionales, ya que aparecen como signos de afirmación y como focalizadores. Aún más polifuncionales son exactamente y precisamente, dado que se usan para la afirmación, la focalización y la reformulación. Por el contrario, las funciones discursivas o pragmáticas de cabal/cabalmente quedan por analizar, ya que solo se ha mencionado su uso afirmativo.

En este sentido, no hay simetría en las funciones pragmáticas y discursivas, y de ahí surge otra pregunta de investigación: ¿por qué, partiendo de una base conceptual común, no todos los adjetivos y adverbios de exactitud parecen haber desarrollado cada uno de los tres usos pragmático-discursivos? 


\subsection{Marco teórico diacrónico: modelos de macrocambios}

El presente apartado está dedicado a los modelos teóricos que describen los procesos de cambio lingüístico. En primer lugar, el proceso de gramaticalización en un sentido estricto (es decir, el proceso que se dirige hacia la gramática) será ejemplificado mediante un caso muy estudiado y citado: la creación del sufijo adverbial -mente. En segundo lugar, analizaremos los procesos que llevan a la creación de valores pragmáticos, como es el caso de los marcadores discursivos: ¿gramaticalización (en un sentido amplio) o pragmaticalización? Definiremos conceptos centrales vinculados a tales desarrollos, como construccionalización y subjetivización. Por último, nos centraremos en la teoría de la cooptation, que describe el surgimiento de los elementos llamados theticals, entre ellos, los marcadores discursivos.

Estos modelos representan, en realidad, «macrocambios», ya que agrupan una serie de cambios en los distintos niveles lingüísticos (fonología, morfología, sintaxis, semántica y pragmática) que se interrelacionan. Por lo tanto, hay solapamientos entre los modelos y su definición depende de qué microcambios concretos se consideran centrales y cuáles no. La interrelación entre cambios semánticos y sintácticos ha sido observada por varios autores:

«La semántica, entendida de un modo amplio, de manera que recubra tanto semántica léxica, como semántica pragmática e incluso significado enciclopédico y visión de mundo, es una parte integral de la sintaxis y un disparador fundamental del cambio sintáctico, y por ello no hay cambios sintácticos puros, en el sentido de que impliquen solo sintaxis o solo forma» (Company Company 2016, 516).

Como puntualiza Hummel (2013c), desde el punto de vista diacrónico, es de esperar que la creación de funciones discursivas esté condicionada e influenciada por las propiedades funcionales de la categoría base (es decir, la categoría de adjetivos y adverbios). En el plano semántico, las unidades con valor discursivo suelen perder algunos rasgos semánticos (semantic bleaching) a la vez que hay persistencia de otros rasgos. Asimismo, es de esperar que pierdan algunas propiedades funcionales y retengan otras (Hummel 2013c, 77).

Antes de resumir cada modelo, mencionemos algunas observaciones generales pertinentes para cualquier tipo de cambio lingüístico. Los cambios sintácticosemánticos suelen ser graduales y ocurren a través de etapas sucesivas. Por esta característica acumulativa (la estratificación), los usos anteriores suelen permanecer al lado de los innovadores por siglos, a veces de manera residual (Company Company 2008, 18). Los siguientes factores, tanto estrictamente 
lingüísticos como externos a la lengua, aceleran o retardan el avance de una innovación (Company Company 2008, 22):

1) Profundidad histórica o antigüedad del cambio en cuestión

2) Aspecto fónico de la forma o construcción innovadora

3) Frecuencia de empleo de las formas o construcciones conservadora e innovadora

4) Tipo de categoría que experimenta el cambio

5) Tipo de sociedad usuaria de la lengua

6) Género textual o tradición discursiva de manifestación del cambio.

A lo largo de nuestro análisis empírico, pretendemos mostrar cuáles de estos factores influyen en los cambios observados en el grupo de adverbios y adjetivos.

\subsubsection{Gramaticalización (tradicional o en sentido estricto)}

En un sentido estricto, la gramaticalización hace referencia a un proceso de cambio en el cual las formas léxicas se convierten en gramaticales o las formas gramaticales se hacen todavía más gramaticales (Traugott/Heine 1991; Traugott 2003; Company Company 2016). La definición más aceptada y citada es la de Traugott (2003):

«The process whereby lexical material in highly constrained pragmatic and morphosyntactic contexts is assigned grammatical function, and once grammatical, is assigned increasingly grammatical, operator-like function.» (Traugott 2003, 645)

El resultado de la gramaticalización son elementos que pertenecen a la gramática y, por lo tanto, cumplen con estas tres características: obligatoriedad, integración paradigmática y significado relacional (Diewald 2011a, 453). En este sentido, dentro de un paradigma gramatical (tiempo, aspecto, persona, etc.), los valores se oponen entre sí y hay que elegir obligatoriamente uno, ya que no se puede omitir la información gramatical. Como significado relacional se entiende que los elementos gramaticales establecen un enlace entre el elemento lingüístico modificado y otra entidad anclada en la deixis del origo (Diewald 2011a, 453-454).

La gramaticalización es un macrocambio, ya que afecta a forma, función, significado y frecuencia de empleo de las formas sometidas al proceso; además impacta muchas veces la sustancia fónica del signo (Company Company 2016, 521). A modo de ejemplo, resumimos brevemente la diacronía del sufijo adverbial -mente, que se considera un caso típico e ilustrativo de gramaticalización tradicional (Company Company 2016, 519). En este proceso, el sustantivo mente pierde su significado propio, queda como indicador modal y finalmente se convierte en un mero afijo gramatical (García Sánchez 2007, 421-424). 
En latín clásico, existían varios procedimientos de formación adverbial, como los sufijos - $\bar{E}$ e -ITER (Karlsson 1981, cap. 2). Sin embargo, en el latín vulgar, este sistema apenas se usaba por presentar demasiada variación y confusión. Como alternativa, se usaban formas perifrásticas con sustantivos abstractos como MODO o VIA, o sustantivos que describen un estado mental: PECTORE, CORDE, ANIMO o MENTE (Karlsson 1981, cap. 3). El sustantivo MENS ‘mente, intención', en su forma ablativa MENTE, se prestaba especialmente a la formación de frases adverbiales, ya que la intención y el estado mental al hacer algo fácilmente se cruzan e interrelacionan con la manera de hacerlo (Karlsson 1981, 43-44).

En latín, el sustantivo femenino MENs funcionaba plenamente como un sustantivo con todas sus capacidades morfológicas y sintácticas (concordancia, flexión, coordinación) y su significado era referencial (la 'mente humana'). En un primer paso, MENTE se fijó en una construcción, precedido por un adjetivo en ablativo femenino singular por concordancia. Gradualmente, adquirió un significado más abstracto (Company Company 2016, 518). Esto es, el significado de MENTE cambió de 'estado mental' a 'modo, manera' (Karlsson 1981, 51).

Las frases adverbiales con MENTE eran muy marginales en los autores clásicos. Fue en el latín tardío cuando aumentaron las formaciones adverbiales con MENTE. La influencia cristiana añadió un ímpetu, ya que el discurso cristiano adoptó muchos adjetivos que típicamente se usaban con MENTE: DEVOTA, PURA, SINCERA, SECURA, etc. (Karlsson 1981, 44-47). Por último, en el español medieval, mente se afijó al adjetivo, aunque se conservó durante bastante tiempo la variación entre la forma fusionada y la ortografía separada (Company Company 2016, 518).

En resumen, MENTE entra en una construcción fija y pierde libertad morfológica, posicional y movilidad. Pierde, pues, autonomía y adquiere cohesión morfológica. Semánticamente, deja de ser transparente: -mente ya no refiere a una parte abstracta del cuerpo humano, sino que adquiere un significado aún más abstracto: el modo de realizar un evento. Además, el adverbio en -mente entra en relación paradigmática con otros adverbios (Company Company 2016, 519).

Uno de los mecanismos implicados en la gramaticalización es el reanálisis, que consiste en la reinterpretación abductiva de la asociación «forma-función» de una unidad (Traugott 2003, 626). Las relaciones y los valores se reinterpretan y así, la construcción se recategoriza (Company Company 2016, 524). Por ejemplo, un sintagma nominal de tipo [adjetivo + mente] se reanaliza como palabra: sintaxis > morfología. La categoría léxica de adjetivo se reanaliza como raíz léxica de un adverbio y el sustantivo mente como afijo: léxico > morfología (Company Company 2016, 524-525).

Así, la gramaticalización como macrocambio afecta a varios niveles lingüísticos: la forma morfológica del adverbio en -mente, su sustancia fónica prosódica (la pausa se pierde o minimiza), su función y su semántica (Company Company 
2016, 521). Según García Sánchez (2007, 425-427), tras la gramaticalización del sufijo -mente, hay una lexicalización de todo el adverbio en su conjunto (adjetivo base + -mente). Dado que -mente se vacía de contenido propio, los adverbios pueden aparecer en otros dominios aparte del modal (por ejemplo, temporal, espacial, etc.) y es el valor léxico del adjetivo base el que dirige el uso del adverbio.

\subsubsection{Gramaticalización en un sentido amplio o pragmaticalización}

La evolución histórica de los marcadores discursivos presenta ciertos paralelismos con la gramaticalización, pero también se distingue en varios aspectos centrales. Llamar gramaticalización al surgimiento de los marcadores discursivos o usar otro término como pragmaticalización no es solo una cuestión terminológica, sino que conlleva consecuencias teóricas para la definición de dichos procesos. En este apartado, resumiremos brevemente las tres posturas principales que se han defendido en la bibliografía (Onodera 2011, 616-620; Heine 2013, 1219-1220; La Rocca 2013):

a) Los marcadores discursivos surgen por gramaticalización.

b) Los marcadores surgen por pragmaticalización (que es distinta a la gramaticalización).

c) La pragmaticalización es un subtipo de gramaticalización.

Para integrar los marcadores discursivos en la teoría de la gramaticalización, algunos autores sostienen que los marcadores del discurso forman parte de la gramática (Pinto de Lima 2002; Traugott/Dasher 2002, 158-159; Brinton/Traugott 2005, 139; Degand/Evers-Vermeul 2015). Para que la gramaticalización abarque también las características particulares de los marcadores discursivos, proponen una noción amplia de gramaticalización (Traugott 1995; Brinton/Traugott 2005, 136-140).

En cambio, los autores que postulan un proceso propio, la pragmaticalización, sostienen que incluir los marcadores discursivos en la gramaticalización supondría una concepción demasiado amplia de gramática (Claridge/Arnovick 2010, 186-187; La Rocca 2013). Según esta postura, los marcadores discursivos serían una categoría fuera de la gramática (Onodera 2011, 616). Asimismo, Ocampo (2006, 317-318) considera que la evolución de los marcadores discursivos no puede considerarse gramaticalización.

Así pues, Claridge/Arnovick $(2010,187)$ definen la pragmaticalización como el proceso mediante el cual una secuencia léxica o una forma concreta de un lexema, en un determinado contexto, pierde su significado proposicional a favor de un significado esencialmente metacomunicativo, discursivo, interaccional; o 
un elemento ya pragmático continúa desarrollando nuevas funciones pragmáticas. Por su parte, La Rocca $(2013,137)$ resume cuatro características que definen la pragmaticalización: cambio de significado por un proceso metonímico; aumento de subjetivización; paso del ámbito de la oración al ámbito extraoracional o discursivo; y aumento de libertad sintagmática y sintáctica.

La tercera postura trata de integrar la pragmaticalización dentro de la gramaticalización al definir la pragmaticalización como la gramaticalización de marcadores discursivos (Diewald 2011a; 2011b). El origen de ambos procesos es el mismo: unidades léxicas conceptuales. Asimismo, los procesos diacrónicos que afectan a todos los niveles lingüísticos son paralelos en la gramaticalización y en la pragmaticalización. Lo que es distinto es el dominio final (target domain) de los dos procesos: la gramática o la pragmática (Diewald 2011a, 456). En este sentido, la pragmaticalización es un subtipo de gramaticalización:

«I suggest that pragmaticalization is a specific instance of grammaticalization which shows the crucial features of grammaticalization processes and is only distinguished from other grammaticalization processes by the functional domain it leads to and by some concomitant structural features (e.g., low degree of syntactic integration). As pragmaticalization (understood in these terms) is one instance of grammaticalization among many others, there is no reason to treat it on par with grammaticalization, i.e., on the same hierarchical level, in a classification of types of language change.» (Diewald 2011b, 384)

Esta postura también es defendida por Brinton (2017, 31-36). Asimismo, Hummel (2012, 359) considera la pragmatización una subclase de gramaticalización, que presupone una concepción más amplia de gramática, incluyendo el ámbito discursivo.

En la creación de marcadores discursivos se suelen observar varios procesos sucesivos. Por ejemplo, Girón Alconchel (2008) insiste en que la creación de marcadores discursivos sigue la pauta lexicalización (colocación) > gramaticalización > lexicalización. También hay autores que consideran que la gramaticalización puede ser un proceso posterior a la pragmaticalización, o a la inversa (La Rocca 2013, 136). Por ejemplo, para Martí Sánchez (2008, 88), la evolución de los operadores pragmáticos comienza con una pragmatización, puesto que dependen del contexto y de la función interpersonal. En casos como de hecho o desde luego, se da un paso más y es posible hablar de gramaticalización, al haber dado lugar a una forma que solo se usa como operador.

No hay, pues, unanimidad en cuanto a la clasificación del proceso de pragmaticalización. La crítica más repetida a la inclusión de los marcadores discursivos en la gramaticalización consiste en que la gramaticalización se ha convertido en una categoría demasiada amplia y, con ello, borrosa. Respecto al supuesto vacío del término, Degand/Evers-Vermeul $(2015,78)$ sostienen que la gramaticalización (amplia) abarca inequívocamente procesos que van en una dirección clara: es la 
evolución de expresiones lingüísticas desde un significado más conceptual, referencial y léxico hacia un estado más funcional, en el cual la expresión marca un sintagma, la oración o el contexto amplio en el que se usa.

A pesar de que no hay unanimidad en cuanto a la denominación, los cambios lingüísticos concretos que comparte la evolución de los marcadores discursivos con la gramaticalización son claros. Los parámetros de gramaticalización observados por Traugott (1995) en el desarrollo de algunos marcadores discursivos son: decategorización, reducción fonológica, generalización, enriquecimiento pragmático y subjetivización (véase más adelante, apartado 1.4.2).

Tanto en la pragmaticalización como en la gramaticalización hay semantic bleaching ('desgaste semántico'). La unidad pierde su significado inherente e independiente del contexto. A medida que se asocia a un contexto determinado, aumenta la dependencia de este contexto, en el cual surge un nuevo significado ligado a funciones subjetivas, textuales o interpersonales (Furkó 2014, 292). Es decir, no hay simplemente una "pérdida» de rasgos semánticos conceptuales, sino que estos se reemplazan por otros rasgos semánticos abstractos, metafóricos o metonímicos (Hummel 2013c, 69).

Según Claridge/Arnovick $(2010,179)$, quienes hablan de pragmaticalización, la pérdida de rasgos semánticos en los marcadores discursivos se compensa por un proceso paralelo de pragmatic strengthening 'enriquecimiento pragmático', que lleva a la convencionalización de los nuevos usos pragmáticos. Asimismo, Martín Zorraquino/Portolés Lázaro (1999, 4059-4062) hablan de «desemantización» de los marcadores discursivos durante su gramaticalización: el significado léxico-conceptual se pierde (parcialmente o del todo) a favor de una función relacionada con la organización del texto, con la expresión de actitudes subjetivas del hablante o con la interacción entre hablante y oyente.

En cambio, hay otra serie de parámetros que no se cumplen en los marcadores del discurso. Los factores que distinguen la evolución de los marcadores discursivos del proceso de gramaticalización en un sentido estricto giran, principalmente, alrededor de los siguientes factores morfosintácticos (Claridge/Arnovick 2010, 180-185; Onodera 2011, 617-618; Heine 2013, 1218-1219; Furkó 2014, 293):

a) La gramaticalización tiende a la integración y fijación sintáctica, pero en el caso de los marcadores discursivos, aumenta la libertad sintáctica y su movilidad; no hay fijación.

b) Los elementos gramaticalizados reducen su alcance sintáctico (scope), mientras que la pragmaticalización conlleva más bien un aumento, una extensión, del alcance.

c) En la gramaticalización, suele haber fusión (por ejemplo, -mente se convierte en afijo), a la vez que la unión de los marcadores discursivos con la oración se vuelve débil, ya que suelen convertirse en unidades extraoracionales. 
Además, los marcadores del discurso pueden eliminarse, ya que no son obligatorios (Claridge/Arnovick 2010, 182; Onodera 2011, 617; Heine 2013, 1218-1219; Furkó 2014, 292-293). Por último, los marcadores discursivos pueden intercambiarse, pero no forman paradigmas cerrados. Por eso, los marcadores discursivos violan un parámetro esencial de la gramaticalización: la paradigmatización (Heine 2013, 1218-1219; Furkó 2014, 292-293).

\subsubsection{Contexto, construcciones y construccionalización}

Por lo general, el proceso de gramaticalización o pragmaticalización no ocurre simultáneamente en todos los contextos de una unidad léxica, sino que avanza primero en un contexto de uso específico (Diewald 2002). Por consiguiente, no es suficiente describir la gramaticalización como cambio de una unidad específica, sino que hay que tener en cuenta la construcción particular en la que ocurre tal cambio (Bybee 2003, 602; Traugott 2003). Asimismo, Company Company (2016, 522-523) insiste en que el contexto es el ámbito en el que se produce una gramaticalización; el cambio no ocurre en unidades aisladas, sino en unidades en un determinado contexto. La gramaticalización ocurre a través de determinados contextos, construcciones y distribuciones (Company Company 2016, 516). En este caso, hablamos del contexto entendido como co-texto: las unidades lingüísticas con las que se combina la unidad que experimenta un cambio.

Tanto la gramaticalización de marcas gramaticales como la gramaticalización o pragmaticalización de marcadores discursivos dependen de un contexto determinado, ya que ocurren dentro de una construcción en la que se puede gramaticalizar un solo constituyente o más de uno; de ahí que la gramaticalización sea precedida por una colocación previa y seguida por una lexicalización posterior:

«Colocación (lexicalización débil, menos estable) $\rightarrow$ Gramaticalización $\rightarrow$ Lexicalización fuerte, estable» (Girón Alconchel 2008, 371).

Heine (2002) distingue principalmente dos tipos de contexto (más específicamente, co-texto): el contexto puente y el contexto de cambio; bridging context y switch context. El contexto puente abarca los usos ambiguos en los que surgen inferencias pragmáticas que llevan a una nueva interpretación, y esta todavía se puede anular (Heine 2002, 84). Los contextos de cambio son aquellos contextos específicos en los que se independiza el nuevo significado: la lectura original ya no es aceptable y el nuevo significado es la única interpretación posible (Heine 2002 , 85). Por ejemplo, gracias al mayor grado de abstracción, que es el resultado de la gramaticalización, los adverbios en -mente pueden construirse con formas 
más diversas y entrar en nuevas distribuciones y construcciones (Company Company 2016, 521).

Del hincapié en la importancia del contexto en el cambio lingüístico surge el modelo de constructionalization o construccionalización (Hilpert 2013; Trousdale 2014; Traugott/Trousdale 2014). No es un proceso necesariamente vinculado a la gramaticalización: por ejemplo, Hilpert $(2013,9)$ propone considerar la construccionalización un modelo de cambio lingüístico más abarcador que la gramaticalización, ya que incluye, entre otros, también procesos de lexicalización.

La definición de construcción es, por lo tanto, más amplia. Según Traugott/ Trousdale (2014), la constructionalization consiste en la asociación convencionalizada de un esquema formal a un significado determinado. En esta misma línea, Company Company $(2016,523)$ define la construcción como «apareamiento de forma y significado arropado en una colocación o distribución exclusiva de ese apareamiento». Un patrón lingüístico es reconocido como construcción si algún matiz de su significado o de su función no es estrictamente deducible de sus componentes o de otras construcciones paralelas. Además, cualquier patrón se fija como construcción, aunque sea completamente transparente, siempre y cuando ocurra con suficiente frecuencia y se memorice como conjunto (Hilpert 2013, 5).

La construccionalización entendida como cambio diacrónico supone, por lo tanto, el desarrollo de funciones, formas o significados particulares de una construcción:

«Constructional change selectively seizes a conventionalized form-meaning pair of a language, altering it in terms of its form, its function, any aspect of its frequency, its distribution in the linguistic community, or any combination of these.» (Hilpert 2013, 16)

Además, la asociación convencionalizada entre forma y significado experimenta un proceso de construccionalización si hereda o adquiere propiedades de un esquema más general y más abstracto (Trousdale 2014). En cuanto a los procesos de gramaticalización, Company Company $(2016,523)$ considera que la construcción particular propicia el inicio del cambio y, por lo tanto, la gramaticalización es, en realidad, una construccionalización de nuevas construcciones más esquemáticas. Basándose en las nociones de bridging context y switch context, la autora propone el siguiente camino de fases o etapas sucesivas de una construcción:

«contexto etimológico > contexto puente (la construcción es ambigua) > contexto de cambio > convencionalización de la construcción > generalización/diversificación (expansión a nuevos contextos)» (Company Company 2016, 523). 


\subsubsection{Subjetivización}

Las unidades léxicas subjetivas codifican explícitamente el punto de vista del hablante, como es el caso de las marcas de deixis o modalidad y los marcadores discursivos (Traugott/Dasher 2002, 21-22). Se trata de «explicit markers of SP/W [Speaker/Writer] attitude to what is said» (Traugott/Dasher 2002, 23). Por ejemplo, ciertos marcadores discursivos tienen un significado procedimental que consiste en expresar la actitud del hablante hacia el contenido de su enunciado (Traugott 2010, 31), por lo tanto, suponen un mayor involucramiento del hablante y un mayor grado de expresividad (Company Company 2004, 4, 8).

Obviamente, hay subjetividad en lexemas que por su propio significado indican una selección subjetiva del hablante (por ejemplo, idiota). Es decir, la subjetividad es un hecho generalizado y palpable en todas las expresiones lingüísticas. La manera en que se construye un contenido - por ejemplo, la estructura informativa (véase apartado 5.1.1 para el concepto de foco) - necesariamente corresponde a la selección subjetiva de recursos lingüísticos por parte del hablante (Cuyckens/Davidse/Vandelanotte 2010, 8-9). Los hablantes no solo transmiten un contenido proposicional, esto es, un contenido informativo, sino que prácticamente siempre expresan también su punto de vista subjetivo, sus actitudes, emociones o valoraciones en relación al contenido proposicional enunciado (Ghezzi 2014, 17).

En un sentido estricto, la subjetivización es un cambio semántico mediante el cual un lexema va adquiriendo, con el tiempo, significados que codifican perspectivas y actitudes del hablante, vinculados más bien al mundo comunicativo del acto comunicativo que a las características del mundo «real» del evento aludido (Traugott/Dasher 2002, 30; Diewald 2011b, 371-373). Dicho de otro modo, es un mecanismo mediante el cual las actitudes, creencias, emociones y perspectivas subjetivas de hablante se incorporan en la gramática y se codifican como significado nuevo (Traugott 2010, 35). El proceso de subjetivización empieza como implicación ocasional que se va generalizando y convencionalizando (Traugott/Dasher 2002; Martí Sánchez 2008, 83). Es decir, el significado pragmático puede gramaticalizarse y convencionalizarse (Company Company 2004, 1).

En este sentido, la subjetivización frecuentemente se vincula a la pragmaticalización o gramaticalización (Company Company 2004; Claridge/Arnovick 2010; Traugott 2010; Fuentes Rodríguez 2016). Traugott (2010, 29) opina que la subjetivización es un proceso independiente de la gramaticalización, pero que ambos están vinculados «for reasons relating to the various functions of grammar». Es más probable que una subjetivización ocurra vinculada a una gramaticalización 
que a una lexicalización o a cambios semánticos en general. ${ }^{9} \mathrm{~A}$ su vez, Company Company $(2004,23)$ considera la subjetivización un subtipo de gramaticalización, que equivale a la pragmaticalización.

La subjetivización como proceso terminado y acabado implica reanálisis del significado pragmático como significado semántico codificado (Traugott/ Dasher 2002, 35). Por lo tanto, según Traugott (2010, 29, 60-61), hay que distinguir entre la subjetividad que pueda aportar un determinado lexema en contextos relevantes como inferencias pragmáticas («pragmatic subjective invited inferences in specific contexts») y la subjetivización como proceso de codificación léxica como significado nuevo («semantization of these invited inferences»). El enriquecimiento pragmático es un prerrequisito para la subjetivización, pero la subjetivización en sí no es pragmaticalización, sino semantización (Traugott 2010, 35). Es decir, hay lexicalización de un nuevo significado subjetivo.

Esta lexicalización es lo que Heine (2002) define como «convencionalización». Es un paso más, después del bridging context y switch context: el nuevo significado ya no depende del contexto específico, sino que aparece en contextos nuevos; el significado original ha desaparecido y hasta podría ser incompatible $\mathrm{u}$ opuesto al nuevo significado. El significado nuevo se ha incorporado como significado codificado, «normal» e «inherente»; es un significado «semántico» de la palabra, no un significado contextual «pragmático» (Heine 2002, 85-86).

La subjetivización se describe principalmente como cambio semántico. Por ejemplo, es un fenómeno semasiológico para Traugott/Dasher (2002, 30-32) y, en concreto, un subtipo de reanálisis semántico (Traugott 2010, 54). Aunque la semántica (pragmática) constituya el motor de cambio en la subjetivización, este proceso también conlleva cambios y consecuencias en la sintaxis del lexema: según Company Company (2004, 2-3), cuanto más subjetiva sea una expresión, menos sintaxis requiere. Asimismo, Traugott $(2010,60)$ y Fuentes Rodríguez (2016) retoman e insisten en la observación de que la subjetivización es fundamental para el desarrollo de funciones sintácticas marginales. Para Hummel (2012, 106), la subjetivización consiste en «técnicas de construcción de una perspectiva subjetiva sobre los hechos relatados» y estas pueden ser también recursos sintácticos como la anteposición.

9 Hay expresiones subjetivas que no presuponen gramaticalización: por ejemplo, verbos de acto de habla ilocutivos (Traugott 2010, 38). 


\subsubsection{Thetical grammar y cooptation}

Otro concepto teórico que explica el desarrollo de determinadas unidades con funciones pragmáticas o discursivas es la cooptation (literalmente 'incorporación, asimilación, apropiación'). En concreto, trata del surgimiento de unidades llamadas theticals:

«Theticals consist of a word, a phrase, a clause, or even a chunk that does not form any syntactic constituent.» (Kaltenböck/Heine/Kuteva 2011, 853)

Este concepto parte de una doble organización lingüística: sentence grammar ('gramática oracional') y thetical grammar. Son dos dominios distintos que juntos forman la gramática del discurso (discourse grammar) (Kaltenböck/Heine/Kuteva 2011). Los theticals son unidades informativas que contrastan con el resto de la oración (llamado anchor, 'ancla') al tener las siguientes características prototípicas (Kaltenböck/Heine/Kuteva 2011, 853-855):

a) Son sintácticamente independientes: no se integran en la oración y no son argumentos de ningún elemento oracional.

b) Se separan prosódicamente del resto de la oración (mediante pausas o entonación): cuentan con un contorno prosódico propio.

c) Su significado es no restrictivo.

d) Tienden a una posición libre y a la movilidad sintáctica.

e) Su estructura interior está formada según los principios de la sentence grammar, pero pueden ser elípticos.

Los theticals son, pues, unidades sintáctica y prosódicamente autónomas. El hablante da un paso afuera de la comunicación lineal para comunicar algo en un segundo plano (Kaltenböck/Heine/Kuteva 2011, 879). Theticals pueden ser tanto estructuras complejas y relativamente largas (inglés I think, I suppose, you know, isn't it?; alemán glaube ich, francés je pense), como palabras simples (like, say, what), además de vocativos, imperativos, interjecciones y aposiciones (Kaltenböck/Heine/Kuteva 2011, 856-857). En el caso de una secuencia de varias palabras, los theticals no pueden partirse, ya que forman bloques «monolíticos» (Kaltenböck/Heine/Kuteva 2011, 864).

Tradicionalmente, algunos theticals reciben denominaciones como elementos periféricos, parentéticos, extraoracionales, disjuncts, etc. Los autores de la propuesta de cooptation prefieren el término thetical, ya que no todos interrumpen una oración, es decir, no solo aparecen en posición parentética. También hay theticals que aparecen al inicio o al final de una oración o como enunciado independiente (Kaltenböck/Heine/Kuteva 2011, 852). 
Consiguientemente, entendemos thetical como hiperónimo que engloba todo tipo de estructuras autónomas y destacadas, entre ellas los parentéticos. El hecho de que las estructuras parentéticas son propensas a desarrollar funciones pragmáticas o discursivas ha sido observado por varios autores. Han sido especialmente estudiados los parentéticos de formas verbales como insisto, creo, digamos, ¿sabes?... (Schneider 2007; Fuentes Rodríguez 2013d; Schneider/Fuentes Rodríguez 2017). Schneider (2015, 278-279) define el paréntesis como un segmento que añade un trozo de información adicional de manera explícita - no solo inferida - interrumpiendo la secuencia lineal del enunciado. No se trata de errores en la comunicación, sino de una estrategia específica que permite al hablante comentar su discurso, expresar su punto de vista o añadir una información sin someterla directamente al juicio del oyente (Schneider 2015, 281). Como observa Hummel (2013c, 78-79), la posición dislocada de segmentos sintácticamente independientes, con entonación parentética y no explícitamente integrados en la oración, es la que permite el surgimiento de interpretaciones pragmáticas, discursivas y de polifuncionalidad.

Asimismo, para Kaltenböck/Heine/Kuteva (2011, 860-861), la función de los theticals suele ser metacomunicativa o metatextual, ya que comentan de alguna manera el discurso o una parte concreta de un enunciado. Los theticals sitúan el enunciado en una perspectiva más amplia, básicamente, de dos maneras: por un lado, organizan el texto al añadir, por ejemplo, explicaciones, comentarios o informaciones sobre el origen de la información, la situación discursiva o el conocimiento del mundo; por otro lado, describen las actitudes del hablante o involucran al oyente en el discurso, es decir, indican interacción entre hablante y oyente (Heine 2013, 1221). En el primer caso, su función es, por lo tanto, metalingüística o metadiscursiva; en el segundo caso, entran en la vertiente pragmática al incluir o la subjetividad del hablante o la relación social entre hablante y oyente. En este sentido, los marcadores discursivos son theticals. La categoría de los theticals es, sin embargo, más amplia: también abarca fórmulas de intercambio social, vocativos, interjecciones, imperativos, etc. (Heine 2013, 1216-1217).

Para el surgimiento de la mayoría ${ }^{10}$ de los theticals, los autores proponen el concepto de cooptation, que definen como

«a packaging strategy whereby a clause, a phrase, a word, or any other unit is taken from Sentence Grammar and is coopted (or re-defined) for use as a thetical» (Kaltenböck/Heine/ Kuteva 2011, 875);

«transfer from pieces of discourse from sentence grammar to thetical grammar, whereby they turn into theticals» (Heine et al. 2017, 818).

10 No todos los theticals se han creado mediante cooptation: algunas interjecciones, muletillas o elementos de contacto ( $\mathrm{hm}$, etc.) no vienen de la sentence grammar (Heine et al. 2017, 827-828). 
Se trata de una operación cognitiva plenamente productiva que ocurre de manera instantánea y espontánea; en cualquier momento, los hablantes pueden usar piezas de la Sentence Grammar para transformarlas en theticals (Kaltenböck/ Heine/Kuteva 2011, 879; Heine et al. 2017, 814). No parece haber límites en el material de la sentence grammar que puede pasar por cooptation: una simple palabra, sintagmas o incluso una oración entera (Heine et al. 2017, 829-830).

Las unidades que han pasado por cooptation muestran varios cambios semánticos y sintácticos: ya no se atienen a la sintaxis de la oración, dado que superan las limitaciones sintácticas de su unidad de origen y se salen de la secuencia lineal de la oración. En un thetical, pueden faltar complementos que serían obligatorios en la sentence grammar, ya que estos son inferidos del contexto. Semánticamente, los theticals son más complejos que la construcción original, ya que su significado se moldea según su propio significado original y el del contexto (Heine 2013, 1221; Heine et al. 2017, 828). En cuanto al alcance o scope, la cooptation conlleva un aumento, porque el thetical no se limita al texto, sino que su ámbito es la situación comunicativa (Kaltenböck/Heine/ Kuteva 2011, 879).

A grandes rasgos, las características de la cooptation coinciden con las técnicas llamadas de discursivización por Hummel (2012, 127-129), quien habla de desvinculación o dislocación sintáctica (por ejemplo, anteposición) y pausas prosódicas (elemento inciso) en el caso concreto de bueno, claro y otros atributos. De hecho, el autor insiste en la gran productividad de las técnicas de discursivización que son responsables de inventarios abiertos y de innovaciones que solo se documentan marginalmente (Hummel 2012, cap. 5). Hummel (2012) usa el término discursivización ${ }^{11}$ en un sentido amplio, que abarca la creación de todo tipo de signos discursivos, no solo marcadores tradicionales, y no solo procesos que se asemejan a la gramaticalización. Es más, Hummel $(2012,112)$ sostiene que la diversidad de técnicas de discursivización (algunas propias de la lengua hablada, otras de la lengua escrita) se refleja en la polifuncionalidad de los signos discursivos resultantes. Consideramos que su concepción de discursivización

11 El término discursivización es especialmente ambiguo: para Claridge/Arnovick (2010, 183185) es un tipo especial de pragmaticalización: la creación de marcadores discursivos o fórmulas habituales a base de material ilocucional (good-bye, bless you), que ya era pragmático antes. Para Hummel (2012, cap. 5) es un subtipo de gramaticalización que coincide, a nuestro modo de ver, con los rasgos descritos para la cooptation. En cambio, Elvira (2015, cap. 9) diferencia discursivización de gramaticalización y describe la discursivización como el proceso de creación de todo tipo de marcadores discursivos; por lo tanto, usa discursivización para procesos que otros autores llaman pragmaticalización. 
como creación productiva y espontánea de signos discursivos sintácticamente desligados coincide más o menos con la idea de cooptation.

Los autores de la propuesta distinguen tres tipos de theticals: instantaneous (instantáneos), constructional (construcciones) y formulaic (fórmulas) (Kaltenböck/Heine/Kuteva 2011, 870). Los instantáneos son totalmente composicionales y transparentes, se forman espontáneamente por cooptation en cualquier momento y en cualquier lugar, algunos se pronuncian una vez y nunca más (Kaltenböck/Heine/Kuteva 2011, 871).

El segundo tipo de theticals corresponde a construcciones que forman patrones recurrentes. Son composicionales, pero muestran una estructura y función esquemáticas: I guess, he promised me, didn’t he (Kaltenböck/Heine/Kuteva 2011, 871). Los constructional theticals han adquirido una representación esquemática en el inventario de construcciones de los hablantes (Heine et al. 2017, 819-820).

Por último, los formulaic theticals son fórmulas no composicionales, no analizables morfosintácticamente, esencialmente invariables y típicamente cortas. A esta categoría pertenecen muchos marcadores del discurso, vocativos, interjecciones, imperativos y formulas sociales (Kaltenböck/Heine/Kuteva 2011, 871872), tales como los marcadores anyway, however, in fact, I mean, you know, what else, in other words (Heine et al. 2017, 820).

Aquellos theticals que se crean instantáneamente son productos de una actividad en «tiempo real», de una cooptation espontánea y novedosa. En cambio, las construcciones y fórmulas ya convencionalizadas pertenecen a un inventario más o menos fijo de unidades más o menos fijadas (Kaltenböck/Heine/Kuteva 2011, 872), ya que son el resultado de cooptation en el pasado: se desarrollan a partir de theticals instantáneos, que a través de su uso frecuente y productivo se construccionalizan (Heine et al. 2017, 820-821).

En el siguiente ejemplo, el thetical it need hardly be said aparece de manera espontánea (es un instantaneous thetical) y en su lugar podrían aparecer muchas otras secuencias: tanto creaciones ad hoc (and this is not really surprising) como fórmulas más fijadas y convencionalizadas (you know):

This may it need hardly be said lead to compromise over the patient's best medical treatments to promote personal and commercial interests (Heine 2013, 1221).

Siempre es un hablante particular el que produce una cooptation. Según Heine (2013, 1240), es difícil determinar cuándo exactamente ocurre cooptation o cuántas veces ha ocurrido en la historia de una determinada expresión. Eso significa que un thetical que se fija y convencionaliza puede haber pasado una sola vez por cooptation y, posteriormente, se expandió a otros hablantes, o más bien varias cooptations independientes dieron un mismo resultado. 


\subsubsection{Sintesis}

Creemos necesario distinguir la gramaticalización de marcas gramaticales como el sufijo -mente de la creación de marcadores discursivos, ya que los microcambios típicos involucrados en las rutas de evolución difieren parcialmente. Para la creación de marcadores discursivos, partimos de la propuesta de una concepción ampliada de la gramaticalización, denominada también pragmaticalización. La lista de los rasgos distintivos entre gramaticalización y cooptation propuesta por Heine $(2013,1222-1223)$ parte de una concepción estricta de gramaticalización (la que crea elementos gramaticales) y no de la versión amplia que incluye la formación de marcadores discursivos. Sin embargo, ya que el modelo de cooptation propone analizar el surgimiento de marcadores discursivos, nos parece necesario compararla con la definición amplia de gramaticalización, a saber, la pragmaticalización. Creemos que todas las propiedades de la cooptation en la Tabla 2 -adaptada de Heine (2013, 1222-1223) - se corresponden también con el concepto de pragmaticalización. En este sentido, estamos de acuerdo con la crítica de Brinton $(2017,37)$ a la teoría de la cooptation, en la medida en que los cambios observados en el surgimiento de marcadores discursivos por cooptation son perfectamente compatibles con una noción ampliada de gramaticalización.

Tabla 2: Microcambios de gramaticalización y cooptation (adaptada de Heine, 2013).

\begin{tabular}{lll}
\hline & $\begin{array}{l}\text { gramaticalización en un sentido } \\
\text { estricto } \\
\rightarrow \text { sufijos gramaticales como } \\
\text {-mente }\end{array}$ & $\begin{array}{l}\text { cooptation y gramaticalización en un } \\
\text { sentido amplio (= pragmaticalización) } \\
\rightarrow \text { marcadores discursivos }\end{array}$ \\
\hline alcance & reducción del alcance & aumento del alcance \\
\hline sintaxis & $\begin{array}{l}\text { decategorización interna y } \\
\text { externa: pérdida de distinciones } \\
\text { morfosintácticas y de autonomía }\end{array}$ & $\begin{array}{l}\text { no hay decategorización externa: } \\
\text { la unidad es sintácticamente } \\
\text { independiente }\end{array}$ \\
& sintáctica & \\
\hline orden de & tienden a limitar su posición, & tienden a liberarse de las restricciones \\
palabras & generalmente adyacente a una \\
& determinada unidad & $\begin{array}{l}\text { de posición, aunque generalmente } \\
\text { prefieren una posición prototípica en el } \\
\text { discurso }\end{array}$ \\
\hline morfofonología & las unidades gramaticalizadas & las unidades con valor discursivo- \\
& tienden a fusionarse con otros & pragmático tienden a separarse de la \\
& elementos de la oración, se \\
& convierten en clíticos o afijos & \\
\hline
\end{tabular}


Tabla 2 (continuada)

\begin{tabular}{lll}
\hline & $\begin{array}{l}\text { gramaticalización en un sentido } \\
\text { estricto } \\
\rightarrow \text { sufijos gramaticales como } \\
\text {-mente }\end{array}$ & $\begin{array}{l}\text { cooptation y gramaticalización en un } \\
\text { sentido amplio (= pragmaticalización) } \\
\rightarrow \text { marcadores discursivos }\end{array}$ \\
\hline prosodia & $\begin{array}{l}\text { pérdida de entonación marcada y } \\
\text { de contorno prosódico propio }\end{array}$ & $\begin{array}{l}\text { unidades autónomas que se } \\
\text { caracterizan por pausas y un contorno } \\
\text { entonativo propio }\end{array}$ \\
\hline semántica & el significado de las unidades & $\begin{array}{l}\text { el significado de los marcadores } \\
\text { discursivos no forma parte del } \\
\text { gramaticalizadas es determinado }\end{array}$ \\
& por su función en la oración & $\begin{array}{l}\text { no restrictivo) } \\
\end{array}$ \\
\hline
\end{tabular}

Aparte de las diferencias mencionadas en la tabla, consideramos que también hay aspectos comunes entre cooptation y gramaticalización en un sentido estricto. El hecho de que la thetical grammar aprovecha material de la sentence grammar explica por qué varias unidades o secuencias ocurren en ambos ámbitos, pero con funciones distintas (Kaltenböck/Heine/Kuteva 2011, 879). Asimismo, la coocurrencia de elementos gramaticalizados con su elemento léxico original es característica de la gramaticalización y se denomina estratificación (layering), como es el caso de la coocurrencia del sufijo -mente con el sustantivo pleno mente (Company Company 2016) o la coocurrencia de adverbios gramaticalizados (pragmaticalizados) como marcadores discursivos con sus correspondientes bases como adverbios de modo.

Rasgos como el enriquecimiento pragmático (pragmatic strengthening) y la subjetivización en los marcadores discursivos son propios tanto de la gramaticalización (Traugott 1995) como de la cooptation: con el paso de un significado anclado en la oración a un significado anclado en la situación discursiva, necesariamente hay un enriquecimiento pragmático que da lugar a la expresión de actitudes del hablante (subjetivización) y a la interacción entre hablante y oyente (Heine 2013, 1235).

Tanto la gramaticalización/pragmaticalización como la cooptation son «macrocambios» que abarcan una serie de cambios particulares en distintos niveles lingüísticos. Como muestra la segunda columna de la tabla, los micro-

12 Tal y como me advirtió Stefan Schneider, no siempre hay una disrupción entonativoprosódica. Por ejemplo, los verbos parentéticos pueden aparecer sin pausas (Schneider 2015, 280-281). Por lo tanto, matizamos esta observación: el estatus sintáctico autónomo de los signos discursivos facilita y posibilita su aparición en un contorno prosódico propio, mientras que las unidades gramaticales como el sufijo -mente pierden esta capacidad. 
cambios particulares que dan lugar a marcadores discursivos encajan en ambos modelos. Como diferencia esencial entre gramaticalización y cooptation se suele postular que la segunda es una operación momentánea y espontánea (Kaltenböck/Heine/Kuteva 2011; Heine 2013; Heine et al. 2017). En cambio, la gramaticalización se concibe como un proceso de cambio gradual que se prolonga a lo largo de siglos: «Grammaticalization phenomena are essentially gradient and variable. They proceed by minimal steps, not abrupt leaps or parametric changes» (Traugott 2003, 626). Aun así, Traugott $(2003,629)$ puntualiza que cada uno de los pasos de reanálisis, por muy pequeños que sean, es abrupto.

Consideramos, pues, que la diferencia básica entre ambos conceptos consiste en cómo se crea el valor pragmático. La pragmaticalización (gramaticalización amplia) ocurre a través de inferencias pragmáticas contextuales; hay una sucesiva generalización y convencionalización de esas mismas inferencias (La Rocca 2013, 137) y un continuum de estructuras y funciones solapantes. Es decir, en la pragmaticalización suele haber contextos ambiguos que sirven de contexto puente, mientras que el salto de sentence grammar a thetical grammar es instantáneo y no presenta estadios intermedios ni usos ambiguos (Heine 2013, 1237). Una de las críticas más comunes al concepto de cooptation consiste en que una documentación diacrónica repentina de un marcador discursivo podría deberse simplemente a datos inadecuados o insuficientes (Brinton 2017, 37), es decir, la creación ad hoc sería un efecto de corpus más que un reflejo fiel de un cambio. Comprobaremos, en el caso de los adjetivos y adverbios analizados en este trabajo, hasta qué punto los cambios observados son abruptos o graduales.

La propuesta de la cooptation se justifica, según Heine (2013), por el hecho de que la gramaticalización o la pragmaticalización no son del todo suficientes para explicar el surgimiento de marcadores del discurso. La cooptation es el primer paso, pero por sí solo no siempre lleva a la fijación y convencionalización de marcadores nuevos. Solamente cuando esta operación se repite varias veces, puede llegar a un cambio gramatical (Kaltenböck/Heine/Kuteva 2011, 883).

Para el desarrollo de marcadores del discurso, la cooptation sería, por lo tanto, un primer paso obligatorio. Es posible que un thetical instantáneo, creado por cooptation espontánea, más adelante se convierta en formulaic thetical, se fosilice y pierda composicionalidad interna. Este desarrollo posterior a la cooptation es compatible con las propiedades descritas para la gramaticalización o la pragmaticalización: el thetical se usa con más frecuencia y en contextos nuevos (extensión); pierde parcial o completamente el significado léxico-conceptual a favor de una función de organización discursiva (desemantización); pierde composicionalidad interna y se convierte en una unidad más fijada (decategorización interna) y también puede perder parte de su sustancia morfológica o fonética (erosión). Por lo tanto, el proceso intermedio entre la cooptation y la 
gramaticalización es la construccionalización: un thetical espontáneo se vuelve gradualmente más esquemático y se convierte en un marcador invariable (Heine 2013, 1223). Como último paso, el proceso de gramaticalización de los theticals abarca, sobre todo, desemantización (semantic bleaching) (Heine 2013, 1238).

En cuanto al papel de la frecuencia de uso, parece que la creación innovadora de un instantaneous thetical no está relacionada necesariamente con un aumento de frecuencia. Es mediante la fijación y extensión de uso que el constructional thetical aumenta su frecuencia. En cambio, un aumento de frecuencia parece ser necesario para la gramaticalización, como es el caso del empleo de -mente (Company Company 2016, 521). Asimismo, Furkó (2014, 296) considera que la alta frecuencia de uso es crucial para la pragmaticalización: cuanto mayor la frecuencia de una unidad, tanto más rápido se desarrolla y más completo será el proceso de pragmaticalización.

En resumen, el concepto de cooptation nos parece útil para describir unidades que cumplen las definiciones de theticals y que tienen funciones discursivo-pragmáticas, pero que no se han gramaticalizado como marcadores del discurso. Sin embargo, el concepto de theticals y cooptation es solamente válido para marcadores discursivos extraoracionales. No vale, por lo tanto, para operadores pragmáticos que siguen integrándose sintácticamente en la oración, como sería el caso de los adverbios de foco.

Para el desarrollo gradual de funciones discursivas o pragmáticas mentendremos el término gramaticalización por ser más habitual que pragmaticalización en la tradición lingüística hispánica (Estellés Arguedas 2009; 2011; Garcés Gómez 2011; 2014; González Manzano 2013; Fuentes Rodríguez 2013a; Loureda Lamas/ Pons Rodríguez 2015). En todo caso, nos parece un término demasiado abarcador y, por lo tanto, nos parece preferible aclarar que estamos hablando de gramaticalización en un sentido amplio, es decir, del subtipo llamado más propiamente pragmaticalización. Consideramos la subjetivización un proceso estrechamente vinculado a este desarrollo.

Heine $(2013,1239)$ propone ampliar el término pragmaticalización para describir el desarrollo de los marcadores discursivos: se trataría de un término que engloba la cooptation seguida por gramaticalización. Sin embargo, consideramos que esta propuesta confunde aún más la definición y delimitación del término de pragmaticalización y su relación con la gramaticalización. Preferimos mantener la separación nítida entre cooptation y gramaticalización, y consideramos la pragmaticalización un subtipo específico de esta última en cuanto al desarrollo de funciones pragmáticas. Al igual que Girón Alconchel (2008) combina etapas sucesivas de gramaticalización y lexicalización, nos parece provechoso combinar, para una posible ruta de creación de marcadores discursivos, etapas 
sucesivas de cooptation y pragmaticalización/gramaticalización (que, además, podría seguirse por una etapa de lexicalización).

Como señala Onodera $(2011,616)$, es necesario analizar la diacronía de cada marcador individual para ver si puede clasificarse como de gramaticalización o no. No es posible postular un proceso $u$ otro para toda una categoría; es decir, los marcadores discursivos pueden surgir por procesos distintos, ${ }^{13}$ algunos se asemejan más a los parámetros de gramaticalización y otros no. En este sentido, nos parece útil tener en cuenta varias propuestas teóricas y seleccionar, para cada caso concreto, un modelo u otro. Consideramos que la gramaticalización o pragmaticalización y la cooptation son simplemente dos caminos de evolución distintos, pero que ambos dan lugar a significados procedimentales: la primera a través de un proceso gradual de convencionalización de inferencias pragmáticas contextuales y la segunda a través de una elipsis instantánea que crea un elemento thetical, que en principio es plenamente transparente y composicional, y posteriormente puede gramaticalizarse.

\subsubsection{Cambios por analogía: el «efecto paradigmático»}

El hecho de que un cambio dentro de un grupo o paradigma no suele ser simultáneo y paralelo en todos los miembros se ha observado en los cambios sintácticos en general:

«El cambio sintáctico nunca impacta a todos los miembros de una categoría en su totalidad ni al mismo tiempo, sino que afecta primero a ciertos ítems de esa categoría en ciertas distribuciones y avanza progresivamente a otros contextos distribucionales y/o a otros ítems.» (Company Company 2016, 515)

Esta observación es generalizable a los procesos implicados en la creación de unidades con valor pragmático-discursivo. Desde el punto de vista diacrónico, la formación de un paradigma pragmático cuenta con procesos de gramaticalización (o pragmaticalización) o cooptation, y de analogía. Cuando un nuevo miembro entra en un paradigma ya existente, probablemente adopte e imite la distribución y los usos de los demás miembros. Generalmente, el miembro prototípico y más antiguo es el que marca las pautas que siguen los miembros recientes. En este caso, la analogía opera como mecanismo de creación de nuevos

13 Por ejemplo, no hay que olvidar el calco de marcadores, por ejemplo latinos, en una determinada tradición discursiva (Pons Bordería 2008; Loureda Lamas/Pons Rodríguez 2015, 339-341). El préstamo léxico es, pues, otra fuente de marcadores discursivos nuevos. 
valores pragmáticos. Estellés Arguedas $(2011,157)$ habla de «gramaticalización a marchas forzadas», ya que los nuevos miembros no solo adoptan el significado procedimental del paradigma, sino también los mismos caminos evolutivos; así, adquieren distribuciones contextuales más amplias por imitación al resto de los elementos del paradigma.

En el caso de los marcadores de digresión por cierto, a propósito, a todo esto/a todas estas, dicho sea de paso, Estellés Arguedas (2011, 212-215) muestra que varios miembros de este paradigma acaban convergiendo en caminos de cambio similares. La pertenencia a un paradigma posibilita caminos de evolución que no serían explicables sin el mecanismo de analogía: los miembros del paradigma siguen rutas de evolución que, en un principio, quedarían fuera de su evolución esperable. En este sentido, determinadas posiciones inesperadas o restricciones pragmáticas solo son explicables por la influencia de los demás miembros del paradigma.

Asimismo, Garcés Gómez (2013a, 311) insiste en que el análisis de la evolución de elementos que pertenecen a un paradigma pragmático no puede realizarse de manera aislada, ya que hay que tener en cuenta cómo se configura un paradigma pragmático y cómo se van distribuyendo los valores a raíz de la incorporación de nuevos miembros. Por ejemplo, la autora estudia el proceso evolutivo de los marcadores de separación (de todas maneras, de todas suertes, de todas formas, en cualquier caso, etc.), que van formando un paradigma pragmático a través de diversos procesos de gramaticalización (Garcés Gómez 2011). Asimismo, Garcés Gómez (2013a) observa que las unidades que se integran en el paradigma de los operadores discursivos matizadores de la veracidad y del enunciado (aparentemente, en apariencia, al parecer, a lo que parece, por lo que parece, dizque, por lo visto, etc.) tienen orígenes diversos, se han incorporado en épocas diferentes y a través de procesos evolutivos distintos (Garcés Gómez 2013a, 275).

De modo similar, Sánchez Jiménez (2013) analiza la incorporación sucesiva de adverbios evidenciales como evidentemente, incuestionablemente, indudablemente, naturalmente y obviamente a través de diversos procesos de gramaticalización o pragmaticalización a partir de distintas bases léxicas. Por último, también Fuentes Rodríguez (2013c) observa que algunos de los operadores escalares están plenamente gramaticalizados (encima, incluso, es más, más aún), mientras que otros están actualmente en pleno proceso de fijación y consolidación (para colmo, por si fuera poco, para más inri).

Denominaremos «efecto paradigmático» a los cambios por analogía dentro de un mismo paradigma: el elemento central (que podría ser el más antiguo) de un paradigma experimenta un cambio -ya sea de gramaticalización/pragmaticalización o de cooptation - y los elementos periféricos adoptan la misma línea evolutiva con algún retraso en el tiempo. Creemos que el concepto de paradigma 
pragmático y cambio paradigmático sirve también para ampliar el modelo teórico de la cooptation, aunque ambos conceptos no se hayan relacionado todavía en la bibliografía. Igual que en el caso de la gramaticalización por imitación, nos parece probable que el efecto paradigmático facilite o propulse la cooptation de un nuevo thetical por imitación a un patrón ya existente.

Asimismo, el efecto paradigmático es pertinente para la construccionalización. La analogía es un factor relevante en la Construction Grammar (Heine/ Narrog/Long 2016, 165). Según Trousdale (2014), la asociación convencionalizada entre una forma y un significado puede deberse a la herencia de propiedades de un esquema más general y más abstracto. La imitación de un esquema ya existente en nuevas construcciones léxicas crea paradigmas regulares.

En conclusión, en cualquier cambio semántico, gramatical y/o pragmático que afecta a un grupo o paradigma de signos equivalentes, cabe suponer un elemento precursor, en cuyo caso la gramaticalización, pragmaticalización, construccionalización o cooptation es innovadora. La evolución de los demás elementos que siguen las mismas líneas evolutivas por un «efecto dominó» sería una gramaticalización/pragmaticalización, construccionalización o cooptation por analogía, esto es, por imitación a un modelo ya existente. Uno de los objetivos del presente trabajo consiste, por lo tanto, en comprobar si este es el caso del grupo de adjetivos y adverbios de exactitud, tanto en su evolución semántica y funcional, como en su evolución pragmática. Además, la incorporación de nuevas unidades a un paradigma pragmático podría conllevar una repartición o especialización interna: cada signo probablemente se especializa en un matiz pragmático peculiar. 